\title{
Carbon mediated catalysis: A review on oxidative dehydrogenation
}

\author{
De Chen ${ }^{\text {a,* }}$, Anders Holmen a, Zhijun Sui ${ }^{b}$, Xinggui Zhou ${ }^{\text {b }}$ \\ a Department of Chemical Engineering, Norwegian University of Science and Technology, N-7491Trondheim, Norway \\ b State Key Laboratory of Chemical Engineering, East China University of Science and Technology, Shanghai 200237, China
}

\section{A R T I C L E I N F O}

Article history:

Received 11 April 2014

Accepted 28 April 2014

Published 20 June 2014

\section{Keywords:}

Oxidative dehydrogenation

Carbon mediated catalysis

Carbon nanomaterial

Ethylbenzene

\begin{abstract}
A B S T R A C T
Carbon mediated catalysis has gained an increasing attention in both areas of nanocatalysis and nanomaterials. The progress in carbon nanomaterials provides many new opportunities to manipulate the types and properties of active sites of catalysts through manipulating structures, functionalities and properties of carbon surfaces. The present review focuses on progresses in carbon mediated oxidative dehydrogenation reactions of ethylbenzene, propane, and butane. The state-of-theart of the developments of carbon mediated catalysis is discussed in terms of fundamental studies on adsorption of oxygen and hydrocarbons, reaction mechanism as well as effects of carbon nanomaterial structures and surface functional groups on the catalytic performance. We highlight the importance and challenges in tuning of the electron density of carbon and oxygen on carbon surfaces for improving selectivity in oxidative dehydrogenation reactions.
\end{abstract}

(C) 2014, Dalian Institute of Chemical Physics, Chinese Academy of Sciences. Published by Elsevier B.V. All rights reserved.

\section{Introduction}

Although carbon materials are often used as catalyst supports, it has been long demonstrated that a variety of carbonaceous materials including carbon nanomaterials such as nanodiamond, carbon nanofiber, carbon nanotubes and graphene can catalyze many different reactions. As early as in 1969 Coughlin [1] reviewed the properties of carbon and its applications as catalysts in many reactions involving hydrogen, oxygen, and halogen. In this early review, the author predicted that carbon with large specific surface area were gaining increasing importance in the control of air and water pollution, in purifying and controlling the general chemical environment, and in certain biomedical applications. All the applications involve adsorption and catalysis, physical-chemical processes which may depend upon carbon's crystalline structure, microscopic physical structure, electronic properties, surface chemistry, and, sometimes, the presence of impurities within the carbon. The most important contribution of this review was to point out the intriguing fact that the catalytic activity of carbons can be correlated to its electronic properties, which range from those of a metal to semiconductor to insulator [1,2]. Activated carbons are active catalysts in different reactions including hydrogenation (metal conductor like catalyst), oxidation (semiconductor like catalyst) as well as polymerization and halogenation (insulator like catalyst). The applications of conventional carbon materials such as activated carbons and carbon molecular sieves as catalysis have also been well reviewed by Radovic and Rodriguez-Reinoso [3,4].

The current most important industrial use of activated carbon as catalysts is for the production of phosgene, followed by the oxidation of nocive gases such as $\mathrm{SO}_{2}, \mathrm{NO}$, and $\mathrm{H}_{2} \mathrm{~S}$ in air pollution control $[3,4]$. The oxidative gas phase dehydrogenation of alkylbenzenes over carbons has also received great attention [3], although no industrial application over a carbon catalyst is reported.

The carbon atom with its $2 \mathrm{~s}^{2} 2 \mathrm{p}^{2}$ electron configuration can form a maximum of four bonds which can be either single, dou-

\footnotetext{
*Corresponding author. Tel: +47-73593149; Fax: +47-73595047; E-mail: chen@nt.ntnu.no 
ble, or triple in the atomic state, resulting in the three hybrid orbitals, viz., $\mathrm{sp}, \mathrm{sp}^{2}, \mathrm{sp}^{3}$, respectively. The bonding geometries, viz., linear, trigonal, and tetrahedral, with respect to $\mathrm{sp}, \mathrm{sp}^{2}$, and $\mathrm{sp}^{3}$ hybrid orbitals, make the chemical properties of carbon very complex, allowing the pronounced tendency to form strong covalent bonds with itself and mostly other main elements. The $\mathrm{sp}^{2}$ carbon nanomaterials, such as carbon nanofibers (CNFs) and nanotubes (CNTs) as well as graphene have gained an increasing attention as catalysts for different reactions due to their peculiar structure and properties. In addition, the surface groups on carbon materials, especially $0-$-, B-, and $\mathrm{N}$-containing involved carbon groups, are of special interest in heterogeneous catalysis [5-7].

The synthesis [8-12] and applications [6-8,13-18] of CNTs and CNFs have been intensively reviewed. The applications of carbon nanomaterials in metal-free catalysis has been recently also reviewed, including reactions of oxidative dehydrogenation, oxygen reduction, hydrogenation and oxidation of hydrocarbons and oxygenates [19-22] as well as hydrohalogenation [23]. CNFs and CNTs as catalysts have been intensively studied in oxidative dehydrogenation reactions. However, a critical review focusing more on the fundamental insights to the effects of the CNF structure and the functional groups on the catalyst properties is highly desired.

Before the detailed discussion of the oxidative dehydrogenation of ethylbenzene, propane, and butane on carbon nanomaterials (Section 3), the progress in the fundamental understanding of adsorption of atomic oxygen, the oxygen molecule, and hydrocarbons on carbons will be summarized in Section 2 , in order to gain a better understanding of the reactions. The activity and selectivity of each reaction will be correlated to the structure and surface chemistry of carbon nanomaterials with and without dopants, which will be discussed based on the reaction mechanism proposed in the oxidative dehydrogenation of ethylbenzene (Section 3.1), propane (Section 3.2), and $i$-butane (Section 3.3).

\section{Adsorption of oxygen, alkanes, and alkens on graphite and CNTs}

Chemisorption in the key phenomenon in catalysis, and the adsorption strength normally directly influences the activation energy of reactions. The knowledge on adsorption of oxygen, hydrogen, and hydrocarbons on carbons is essential for a better understanding of reactions on carbon surfaces. However, this has not been investigated in detail so far, and relatively few studies have been performed which will be summarized below.

As discussed in many reviews $[3,4,6,17,18,20-22]$, the surface chemistry on carbon is complicated involving many different oxygen groups shown in Fig. 1, which can be classified into acidic and basic oxygen groups [24,25]. The catalytic behavior of carbon-based catalyst is often related to the oxygen-containing surface groups [25-29]. The surface reactivity, especially involving oxygen groups, is therefore an extensively studied field of carbon-based materials [17,25,28,30,31]. However, the active sites on carbon surfaces are less understood due to the diverse functional surface groups and their dynamic

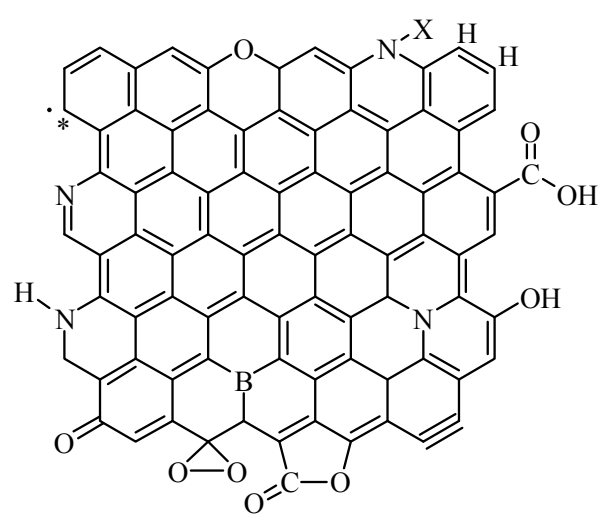

Fig. 1. Representation of the surface chemical features that exist, to a greater or lesser extent, in the graphene layers of flat $s p^{2}$-hybridized carbon materials, including carbene- and carbyne-type free edge sites; carboxyl-, lactone-, quinone-, pyrone-, and phenolic-type oxygen functionalities; delocalized unpaired $\pi$ electrons; nondissociatively adsorbed $\mathrm{O}_{2}$ on carbene-type sites; and doped $\mathrm{N}$ and $\mathrm{B}$ functionalities [36].

changes during the reaction on carbon-based materials. The functionalization of carbon materials and characterization of surface oxygen groups have been intensively studied and reviewed by several authors [32-34]. The characterization of surface oxygen groups is highly complex due to the large variety of groups (Fig. 1) that can coexist in relatively small amounts $[6,30,34]$. The surface oxygen groups can be characterized by several methods, e.g. acid-base titration, infrared (IR), temperature programmed desorption (TPD), and X-ray photoelectron spectroscopy (XPS) [17].

The adsorption of oxygen on highly oriented pyrolytic graphite (HOPG) and bundles of single-wall carbon nanotubes (SWNTs) was studied experimentally using thermal desorption spectroscopy at $28 \mathrm{~K}$ [35]. The low-coverage binding energy of oxygen adsorbed on SWNT bundles, $18.5 \mathrm{~kJ} / \mathrm{mol}$, is $55 \%$ higher than the low-coverage binding energy on HOPG, $0.012 \mathrm{~kJ} / \mathrm{mol}$. The character of the oxygen-SWNT interaction should therefore be of van der Waals type which suggests that the observed oxygen species are physisorbed.

Density functional theory (DFT) in conjunction with slab models and periodic boundary conditions has been used to investigate the adsorption of $\mathrm{O}$ atoms and $\mathrm{O}_{2}$ molecules on graphite and nanotube surfaces [37]. Different adsorption configurations of $\mathrm{O}$ and $\mathrm{O}_{2}$ on the graphene surface and SWNT surface are investigated and the most stable configurations are summarized in Fig. 2I.

An 0 atom interacts with the graphene surface to give rise to a highly stable spin singlet epoxide-like structure (Fig. 2I(a)), consistent with experimental findings. The optimized structure has $\mathrm{C}-\mathrm{O}$ distances of $1.472 \AA$, and the $\mathrm{C}-\mathrm{C}$ bond in the three-membered ring is elongated to $1.500 \AA$ compared to the $1.420 \AA$ value in graphite itself. The adsorption heat is estimated to be $44 \mathrm{kcal} / \mathrm{mol}$. For the nanotube surface, as for the curved graphene surface, the singlet epoxide structure at the outer surface (Fig. 2I(b)) is found to be most stable and the estimated adsorption heat is $69 \mathrm{kcal} / \mathrm{mol}$ [37].

The chemisorbed $\mathrm{O}_{2}$ has a four-membered ring system (Fig. 2I(c)), with C-O bond lengths of $1.50 \AA$ and associated $0-0$ and 


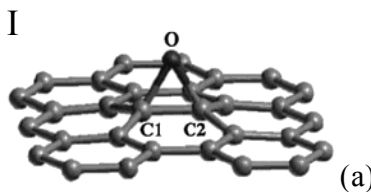

(a)

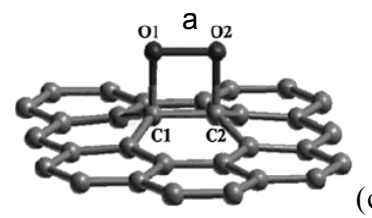

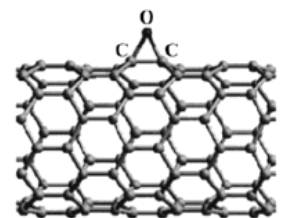

(b)

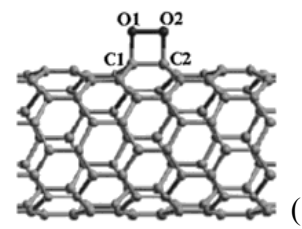

II

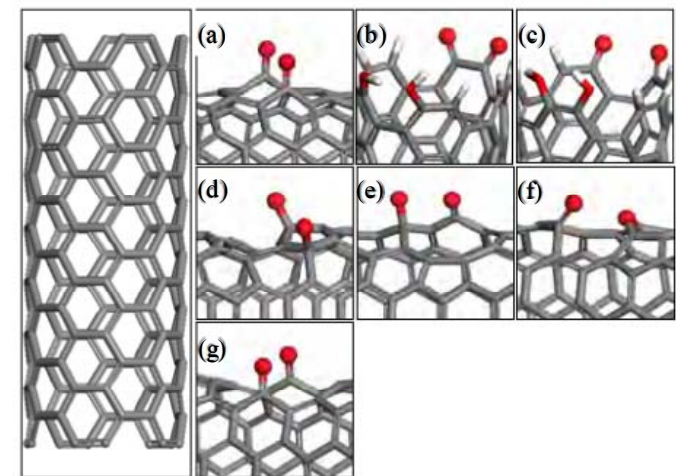

Fig. 2. I: Chemisorption configurations of an $\mathrm{O}$ atom $(\mathrm{a}, \mathrm{b})$ and an $\mathrm{O}_{2}$ molecule (c,d) on the graphene surface and the SWNT surface, respectively [37]. II: Optimized structure of 8-layer armchair (5,5) SWNT model and seven oxygen-modified CNT catalyst models. (a) o-pr-CNT; (b) o-cl1-CNT; (c) o-cl2-CNT; (d) o-dsw-CNT; (e) o-d $\mathrm{d}_{1}-\mathrm{CNT}$; (f) o- $\mathrm{d}_{3}-\mathrm{CNT}$; (g) o-d $\mathrm{d}_{4}-\mathrm{CNT}$. $\mathrm{C}=$ grey, $\mathrm{O}=$ red, and $\mathrm{H}=$ white. pr-CNT = pristine CNT, The structural defects considered are the Stone-Wales defect (o- $\mathrm{d}_{\mathrm{sw}}-\mathrm{CNT}$ ), single vacancy (o-d $\mathrm{d}_{1}-\mathrm{CNT}$ ), and multiple vacancies (o-d3-CNT and o-d4-CNT) [38].

C-C bond lengths typical of those of singly bonded species. This species is metastable and highly unstable on graphite and on the inner surface of the nanotube. However, on the outer SWNT surface (Fig. 2I(d)), it is calculated to be unstable (endothermic) by only $10.2 \mathrm{kcal} / \mathrm{mol}$. The adsorption of $\mathrm{O}_{2}$ to form these chemisorbed species is predicted to have large $(50 \mathrm{kcal} / \mathrm{mol})$ barriers.

DFT calculation predicts that a very large barrier exists for formation of chemisorbed species on ideal surfaces of graphite and CNTs. The defects and edge sites are then important for chemisorption on graphite and carbon nanofibers. An experimental investigation of chemisorption of oxygen on clean carbon surfaces with defects that were introduced by burn-off in air at high temperatures [39]. Results indicated two types of active sites. The activation energy for chemisorption of oxygen on type 1 active sites is considerably low, only $7.4 \mathrm{kcal} / \mathrm{mol}$. An $0^{16} / 0^{18}$ kinetic isotopic analysis revealed that an isotopic effect existed in $\mathrm{O}_{2}$ chemisorption, indicating dissociate adsorption of oxygen molecules on the active sites. The adsorption rate was found to be well described by the equation $k C n_{\infty}(1-\theta)^{2}$, where $k$ is the rate constant, $C$ is concentration of oxygen in the gas phase, $n_{\infty}$ is saturation site coverage relating to the number of type 1 active sites, and $\theta$ is the site coverage of oxygen. The pre-exponential factor is estimated to be $7.1 \times 10^{9}$ by kinetic data fitting. A value of the pre-exponential factor of this magnitude is equivalent to an experimental entropy of activation of about 39 e.u ( $\left.0.163 \mathrm{~kJ} \mathrm{~K}^{-1} \mathrm{~mol}^{-1}\right)$ [39]. An entropy of activation calculated from the absolute rate theory agrees well with the experimental value only for an immobile activated complex which has at most one limited degree of rotational freedom [39]. The authors suggested that the two types of active sites could be related to two types of edge sites on graphite [39]. The termination of graphene sheets in the graphite is not always perfect as arm chair or zig-zag. High resolution TEM image [40] of graphene edge revealed existing of carbon fragments (typically 1-2 carbon atoms) on the edge of graphene sheet, mostly methyl and ethyl groups. The type 1 site could be lactone groups formed with carbon fragments, and this type of oxygen sites is very active. The oxygen adsorbed on type 2 sites could primarily involve the formation of carbonyl groups at conven- tional arm chair and/or zig-zag carbon configurations. Type 2 sites were found to be active at higher temperatures than type 1 sites for oxygen desorption, indicating higher activation energy for the type 2 site. It means that that the site termination of the graphite sheet could have a significant effect on the activity and selectivity for oxidative dehydrogenation. It is in good agreement with the results of Sherman et al. [41] who showed theoretically that the activation energy for dissociative chemisorption of oxygen on carbon was markedly dependent upon the carbon-carbon spacing. They predicted a minimum in activation energy for a carbon-carbon spacing of about $3.5 \AA$. At very high spacing of the carbon atoms, the molecule must effectively be dissociated prior to adsorption. As a consequence, the activation energy is high and approaches the heat of dissociation of the molecule $\left(119 \mathrm{kcal} / \mathrm{mol}\right.$ for $\left.\mathrm{O}_{2}\right)$. At very small spacing of the carbon atoms, the activation energy is again high because adsorption is hindered by repulsion forces. The possible structures and reactivity of the two types of oxygen groups will further be discussed in Section 3.3.

The activation of molecular oxygen is a sequence of events in which oxygen is first molecularly chemisorbed, reduced to a peroxide-like species by carbon $\pi$ electron and dissociated into two $0^{-}$species. Then these species can diffuse into defects or edges such as armchair or zig-zag edge sites, where they are reduced to $\mathrm{O}^{2-}$, form covalent bonds to carbon and give back the initial $\pi$ electrons to the conduction electron system of the well-ordered carbon [42], such as CNFs and CNTs. Chemisorbed $\mathrm{O}^{2-}$ on different carbon sites are expected to have different activities towards oxidation reactions. Chemisorption of atomic oxygen on edges and defects is quite strong and the adsorbed species are immobile [39]. A recent DFT investigation [43] supports this hypothesis where the oxidation of zig-zag carbon with molecular oxygen has extremely high activation energy ( 149-207 kJ/mol), while oxidation of armchair carbon has a moderate activation energy of $(\sim 75 \mathrm{~kJ} / \mathrm{mol})$.

The nature of the oxygen species on the surface of oxides involved in the reaction has been proved to play a significant role in determining the selectivity [44] in metal oxides catalyzed oxidative dehydrogenation. Different adsorbed-oxygen species are formed through a series of equilibria established 
with gas phase oxygen:

$$
\mathrm{O}_{2} \text { (gas) } \leftrightarrow \mathrm{O}_{2} \text { (ads) } \leftrightarrow \mathrm{O}_{2}-\text { (ads) } \leftrightarrow \mathrm{O}_{2}{ }^{2-} \text { (ads) } \leftrightarrow 2 \mathrm{O}^{-} \text {(ads) } \leftrightarrow 2 \mathrm{O}^{2-} \text { (lattice) }
$$

The oxygen species can be classified into two types, namely electrophilic and nucleophilic. Species are gradually enriched in electrons during the surface reactions from $\mathrm{O}_{2}^{-}$(superoxide) to $\mathrm{O}^{2-}$ state, varying from electrophilic to nucleophilic. Electrophilic oxygen including species such as $\mathrm{O}^{-}$(oxide), $\mathrm{O}_{2^{-}}$(superoxide), and $\mathrm{O}_{2}{ }^{2-}$ (peroxide), are electron deficient and attack the electron-rich regions of hydrocarbon molecules (for instance $\mathrm{C}=\mathrm{C}$ double bonds) during oxidative dehydrogenation. It would be responsible for deep oxidation through a rupture of the carbon skeleton and a formation of degradation products [44]. Nucleophilic type oxygen $\mathrm{O}^{2-}$ with electron rich state is preferred to catalytic $\mathrm{C}-\mathrm{H}$ bond cleavage. In addition, olefin molecules are considered as basic or nucleophilic due to their high electron densities at $\pi$ bonds. Therefore they are weakly adsorbed on basic oxygen groups, resulting in lower reactivity and thus high selectivity to olefins [44].

The possibilities to study the function of oxygen on carbon mediated catalysts on carbon materials with greater precision than in metal oxide systems have been illustrated. There is neither lattice nor structural oxygen, but only oxygen at active sites. The function of oxygen heteroatoms in molecular catalysts is reproduced by defects of bent graphitic sheets, namely carbon nanotubes [45] or edge sites in graphene and CNFs [46]. All types of oxygen species on metal oxides exist on carbon surfaces except for lattice oxygen. On carbon materials, nucleophilic $\mathrm{O}^{2-}$ oxygen species exist as quinone groups. A recent DFT work [38] has clearly revealed the orbitals of the CO group were conjugated with the CNT $\pi$ orbitals, which is the main factor that determines the total charge of the group, where CNT serves as an electron reservoir. The configurations of $\mathrm{CO}$ groups are illustrated in Fig. 2II. The results indicate that the charge of $\mathrm{C}$ is more sensitive to the local structural environment than $\mathrm{O}$ [38]. In general, the $\mathrm{CO}$ groups can be divided into three categories with total charges of about $-0.2,0$, and $+0.2 \mathrm{e}$ for the $\mathrm{C}-\mathrm{O}, \mathrm{C}=\mathrm{O}$, and $\mathrm{C}-\mathrm{O}-\mathrm{C}$ groups, respectively. It varies from nucleophilic to electrophilic, and the reactivity of CO groups is clearly related the charge of the CO group [38]. The electron density of oxygen species and thus their reactivity can be tailored by means of varying local electron density of carbon atoms at active sites through tuning terminal configuration of graphene sheets, defects or doping of graphite sheets. This issue will be discussed in more detail in the Section 3 .

Oxidation protection has long been intensively studied for protecting carbon/carbon composites for applications in aircraft barkes [47]. Active site poisoning by $\mathrm{P}, \mathrm{B}$, and $\mathrm{Cl}$ compounds [48] is one of the approaches for oxidation protection, which has been explored afterwards to selectively poisoning of certain sites for improving selectivity in oxidative reactions. In situ transmission electron microscopy provided a direct observation of the process showing that at higher temperatures phosphorus species bonded preferentially to the graphite "armchair" [49] faces leaving the "zigzag" [50] faces vulnerable to attack by oxygen [51]. Formation of a chemical bond between the phosphorus and graphite edge atoms at high temperatures were also evidenced by XPS [48] and FTIR studies
[52]. In contrast, it has been revealed that carbon sites in the zig-zag faces are preferentially poisoned by the strongly bonded adsorbate [53]. Details on the properties of B and P doped carbon materials have recently been summarized [54].

In addition to adsorption or bonding of heteroatoms such as $\mathrm{O}, \mathrm{B}, \mathrm{P}$, adsorption of alkene and alkene on carbons is virtually important for a better understanding of reaction mechanism on carbon surfaces. Hoffman et al. [55] studied chemisorption of alkanes and alkenes $\left(\mathrm{C}_{1}-\mathrm{C}_{4}\right)$ on active surface sites. The carbon used in this study was Graphon, a granular graphitized carbon black, as well as Graphone with different degree of burn-off to increase the edges or defects. The chemisorption of hydrocarbons on graphitized carbon black is of the Langmuir type, with saturation reached at hydrocarbon pressure less than $0.7 \mathrm{~Pa}$ at $573 \mathrm{~K}$. No hydrogen was seen in the gas phase, meaning that if adsorption is dissociative, hydrogen also chemisorbs. In order to better understand the chemisorption of hydrocarbons and, in particular, to determine whether the various molecules occupied the same sites, a series of blockage experiments was conducted for each pair of gases. It was found that the hydrocarbons studied lay flat on the surface and occupied the same sites to varying degrees. Typical site coverages of hydrocarbons on different carbon materials are summarized in Table 1.

The amount of chemisorbed alkenes is typically two or three times of the amount of alkane adsorbed, and $\pi$ electron interaction between alkenes and graphite plays an important role for the alkene chemisorption. The amount of chemisorption increases with increasing carbon number. Moreover, experimental results where the adsorbed amount increases with the increase in defect sites generated by burn-off also indicated that the defects are important sites for adsorption of hydrocarbons.

It was found that chemisorbed hydrocarbons did not desorb at the adsorption temperature even during evacuation. Upon heating, the chemisorbed species thermally crack before desorbing with the principle gas phase product being $\mathrm{H}_{2}$. Hydrogen adsorption was found to be much weak than hydrocarbons [55]. Recently, Schlögl and coworkers [56] have investigated the adsorption of propane and propylene on multiwalled CNT catalysts by using calorimeter (Fig. 3). Four types of adsorption site on the CNT surfaces were classified: (a) Homogeneous high-energy sites that react reversibly with propane and irreversibly with propylene; (b) Heterogeneous, lower energy sites

\section{Table 1}

Chemisorption of selected gases on graphon samples of different active surface area at 573 and $873 \mathrm{~K}$ [55].

\begin{tabular}{lrccccc}
\hline \multirow{2}{*}{ Sample } & Burn-off & \multicolumn{2}{c}{ Area covered $\left(\mathrm{m}^{2} / \mathrm{g}\right)$} & \multicolumn{2}{c}{ Area covered of total (\%) } \\
\cline { 3 - 4 } \cline { 6 - 7 } & $(\%)$ & $313 \mathrm{~K}$ & $873 \mathrm{~K}$ & & $313 \mathrm{~K}$ & $873 \mathrm{~K}$ \\
\hline Propylene & 5.2 & 0.41 & $0.33^{*}$ & 0.49 & 0.40 \\
Ethylene & 11.0 & 0.68 & $0.60^{*}$ & 0.74 & 0.64 \\
& 5.2 & 0.24 & 0.37 & 0.28 & 0.44 \\
Propone & 11.0 & 0.44 & 0.78 & 0.56 & 0.84 \\
& 5.2 & 0.12 & - & 0.14 & - \\
Methane & 11.0 & 0.38 & 0.42 & 0.41 & 0.46 \\
& 5.2 & 0.02 & 0.14 & 0.02 & 0.17 \\
& 11 & 0.02 & 0.43 & 0.02 & 0.47 \\
\hline
\end{tabular}

*Error due to cracking. 


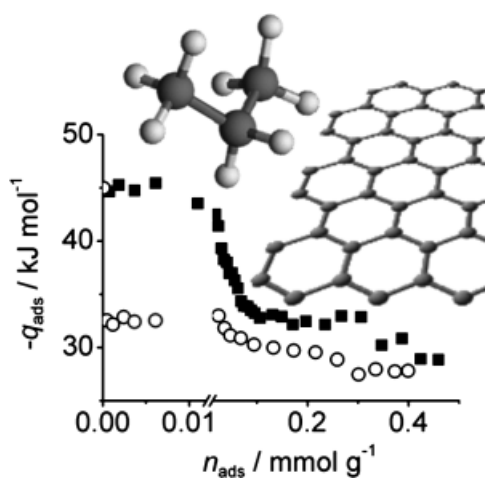

Fig. 3. Adsorption heat of propane and propene as a function of site coverage on CNT [56].

that react reversibly with propane and irreversibly with propylene; (c) Sites containing oxygenated species that interact weakly and reversibly with both propane and propylene; (d) Low-energy sites free of oxygen corresponding to the graphitic carbon base. Recent DFT investigations suggested a very low adsorption heat of propane $(1.37 \mathrm{kcal} / \mathrm{mol})$ on the graphene basal carbon.

A study using immersion calorimeter revealed that the curvature of the graphene sheets of in the CNTs increases the adsorption strength of aromatic compounds compared to flat graphite surfaces [57]. The $\pi-\pi$ stacking interactions were formed between the organic chemicals and CNT surfaces. The number of oxygen groups on CNTs seems to modify the electron density of their surfaces and therefore the interaction mechanism with the adsorbates.

In a summary, these studies point out the challenges in oxidative dehydrogenation of hydrocarbons, namely the higher reactivity of the products than the starting materials, which leads to a low selectivity. The defect and edge sites of carbon materials play a significant role in determining of the formation of oxygenation groups and their properties. The space between the carbon atoms, fragments of carbon on the edge sites as well as the curvature of nanotubes or fibers could influence the electro density of carbon atoms on the edge or defects, thus the electron density of oxygen on carbon surfaces, making oxygen electrophilic or nucleophilic. The curvature of the graphene sheets and the oxygen surface groups influence the interaction between the organic chemicals and carbon materials. As a consequence, the structure of carbon nanomaterials, amount and type of doping species are expected to influence the activity and selectivity of oxidative dehydrogenation, which will be addressed in Section 3. More fundamental studies of the active sites and adsorption of oxygen, alkane, and alkene on the carbon nanomaterials are essential for the development of more selective catalysts.

\section{Carbon-mediated oxidative dehydrogenation reactions}

Oxidative dehydrogenation of hydrocarbons is an attractive process due to its advantages over the conventional endothermic dehydrogenation reaction [58]. Transition metal oxides have been widely used as catalysts for the conversion of al- kanes to alkenes. Lattice oxygen in the oxides plays an important role in the reaction. However, there is a formidable challenge for the selectivity of oxidative dehydrogenation that the product olefins are much more active than the reactant paraffins, leading to deep oxidation to $\mathrm{CO}$ and $\mathrm{CO}_{2}$. Many research groups have been devoted to the development of new catalysts and new technologies to overcome the main challenge in oxidative dehydrogenation. The main progress in the field has been covered in reviews [20,54,59-61]. Various metal-free carbon materials have also been tested as catalysts, exhibiting higher activity and selectivity at mild operating conditions, and early work using conventional carbon such as activated carbon were reviewed previously [3,4]. However, an increasing attention has recently been focused on the use of carbon nanomaterials such as nanodiamonds [62-64], CNTs $[9,11,12,15,17$, $18,25,35,37,45,56,57,63,65-97]$, and CNFs [46,82,98-105] as catalysts for oxidative dehydrogenation due to their high activity and stability $[19,20,54]$. Carbon as the catalytic substance has significant advantages over the conventional metal-supported systems owing to the unique controllability of both its surface acidity/basicity and $\pi$ electron density through surface functionalization. In a carbon material it is the short- and long-range ordering of atomic carbon that essentially determines the macroscopic properties (e.g. thermal and electronic conductivities, combustibility) and thus its long-term performance in any potential industrial process [106]. The nanostructure of CNF has a very significant effect on the catalyst behavior [45,62,66,78,100,101,107,108]. In addition, different structured carbon nanomaterials have been used as model systems to elucidate reaction mechanism $[45,106]$.

A representative summary of carbon-mediated oxidative dehydrogenation of various hydrocarbons is listed in the Table 2 . The types of carbon nanomaterials and typical reaction conditions are also presented. Oxidative dehydrogenation of ethylbenzene (Section 3.1), propane (Section 3.2), and butane (Section 3.3) will be discussed in terms of the influences of structure and surface chemistry of carbon nanomaterials on the activity and selectivity. A comparison with conventional activated carbon will be given.

\subsection{Carbon mediated oxidative dehydrogenation of ethylbenzene (ODE) to styrene}

The direct dehydrogenation of ethylbenzene to styrene is one of the ten most important industrial processes in petrochemical industry. The process uses a K-promoted Fe catalyst at $870-930 \mathrm{~K}[108,111]$. The process is endothermic and thermodynamically limited. The reactor is often operated at low pressure to increase the conversion, which is limited by equilibrium. Excess of steam is often used to lower the partial pressure of ethylbenzene, to reduce coke formation during the reaction and to provide heat. However, generation of steam is very energy consuming, and use of excess steam reduces also the energy efficiency [58].

The oxidative dehydrogenation (ODH) of ethylbenzene could be a promising alternative in which the hydrogen generated is directly oxidized making the overall process exothermic 
Table 2

Examples of oxidative dehydrogenation of hydrocarbons.

\begin{tabular}{lllll}
\hline Reactant & Carbon nanomaterials & $T / K$ & Comments & Ref. \\
\hline Ethylbenzene & Soot, graphite and CNF & 820 & Better stabilized activity and better stability; the reaction mechanism & {$[108]$} \\
& Graphite, CNF and onion like carbon & 790 & Best yield of styrene on onion like carbon & {$[107]$} \\
& CNT and onion like C & 790 & Structure-performance relationship & {$[66]$} \\
& Different Structured CNF & 673 & Structure-performance relationship, and best yield of styrene on fishbone & {$[46]$} \\
& Nano diamond, onion & 788 & sp $^{3}$ C led to C-C cleavage, sp C lead to styrene & {$[62]$} \\
Propane & CNF/carbon felt & 650 & Stable in the structured CNF composite reactor & {$[104]$} \\
& CNFs, B/P-CNFs & 773 & Reach a yield of propene about 16\%.P enhanced reaction & {$[100,101]$} \\
& CMK & 723 & Stable propene yield of 11\% & {$[109]$} \\
Isobutane & Graphene oxides & & Site dependent catalyst activity of graphene & {$[110]$} \\
Ethane & CNT & 673 & NO selective activation of CNT, 4\% propene yield, at 8\% conversion & {$[83]$} \\
\hline
\end{tabular}

[108]. A number of catalysts such as active alumina [112], mixed-oxide [113], and phosphates [114] have been applied as catalysts for ODE, and the accumulated carbon layers deposited on catalyst surfaces have been identified as the real active catalysts converting ethylbenzene (EB) to styrene (ST). Therefore, various carbon-based materials have been tested as catalysts, providing higher activity and selectivity compared to those as-stated catalysts under mild operating conditions (623-673 K) $[59,60]$. However, deactivation of these carbon catalysts becomes a main problem since coke deposition on catalyst surfaces changes their initial physico-chemical properties, and since the carbon-based catalysts are relatively sensitive to oxygen.

Schlögl and coworkers $[31,66,108]$ pioneered the applications of nanocarbons to ODE. The main advantages of the carbon nanomaterials are the high crystallinity thus the high resistance against the oxidation. The well-defined edge structures make it suitable as the model system to elucidate the reaction mechanism, as well as to provide guidelines for catalyst design aiming to increasing the selectivity of styrene. In the following Sections 3.1.1 and 3.1.3, the effects of carbon structures and surface chemistry will be discussed, respectively, in terms of activity and selectivity of the oxidative dehydrogenation of ethylbenzene reaction. At the end, the reaction mechanism will be summarized.

\subsubsection{Effects of surface chemistry}

In the reviews of Radovic and Rodriguez-Reinoso [3,4], the authors have pointed out that the optimization of carbon catalysts - both for ODH and for other applications - would benefit from more detailed surface chemistry studies. The importance and evidence of oxygen on the carbon surfaces were reviewed by Lisovskii et al. [112], where the mechanism of catalysis of dehydrogenation of alkylbenzene on both carbonaceous deposits and activated carbon were addressed. The reaction mechanism was found to be similar on both carbon materials, pointing out the importance of the surface oxygen for the reaction.

XPS is the one of the most powerful tool to identify the type and the amount of the surface oxygen groups [17,25]. Figure 4 displays the $01 s$ XPS spectrum of a CNF catalyst after oxidative dehydrogenation of ethylbenzene [108]. A very weak signal can be seen at $530.2 \mathrm{eV}$ which points to the presence of strongly basic surface oxygen groups, for example, quinoidic or ketonic groups. Another weak signal at $533.5 \mathrm{eV}$ is attributed to adsorbed water [107]. The deconvolution of the $01 s$ spectrum of the onion-like nanocarbon [61] and carbon nanotubes [45] after the reaction revealed three different chemical environments for oxygen, which could be assigned to $\mathrm{C}=\mathrm{O}(530.7 \mathrm{eV})$, $-\mathrm{OH}(532.5 \mathrm{eV})$, and adsorbed water (533.8 eV). The inserted section in the Fig. 4 shows a comparison of oxygen groups before and after oxidative dehydrogenation of ethylbenzene. Before the reaction the $\mathrm{OH}$ group is dominating, while $\mathrm{C}=0$ groups are the dominating after the reaction. The detection of strong basic groups after the catalytic reaction points out the importance of these groups for the dehydrogenating function in the oxidative dehydrogenation.

TPD is often used to characterize oxygen groups on carbon surfaces. The carboxyl, carboxylic anhydride, peroxide, and lactone groups can be measured through the release of $\mathrm{CO}_{2}$ at different temperatures, while the carbonyl groups such as quinoidic or ketonic groups can be measured through the release of CO [115]. Pereira et al. [65] demonstrated that the basic groups are associated with the activity of active carbon as catalysts in oxidative dehydrogenation of ethylbenzene by a TPD method. Zhao et al. [46] used the TPD-MS method to compare the quantity of oxygen-containing groups, and to qualita-

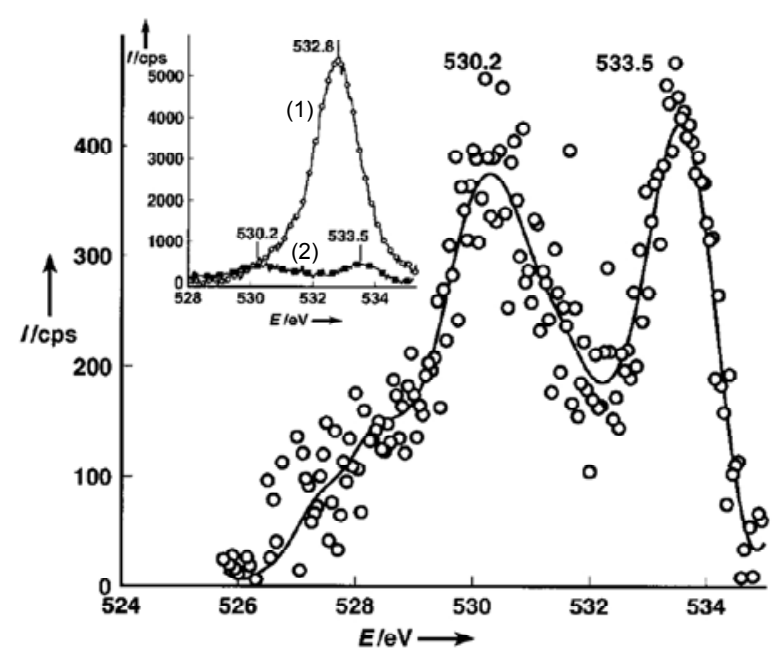

Fig. 4. $01 \mathrm{~s}$ XPS spectrum of the carbon nanofilaments after oxidative dehydrogenation of ethylbenzene. The inset shows a comparison of the spectra before (1) and after (2) the catalytic reaction [108]. 
tively identify the surface groups. TPD-MS spectra for tested CNFs with different graphene sheet orientations after $7 \mathrm{~h}$ reaction showed that CO mostly desorbed at high temperatures (above $773 \mathrm{~K}$ ), whereas desorbed $\mathrm{CO}_{2}$ is strongly dependent on the edge structures of carbon nanofibers in the temperature range of 673-1173 $\mathrm{K}$. The amount of desorbed CO was significantly higher than the one of $\mathrm{CO}_{2}$. The desorbed $\mathrm{CO}$ at higher temperatures can be ascribed to the decomposition of quinone/carbonyl groups (basic groups) [24,116]. These results suggest that the basic groups are preferentially developed during the reaction mediated by oxygen. Moreover, Zhao et al. [46] observed that the activity of the CNFs increased concurrently with the amount of $\mathrm{CO}$ desorbed, thus the amount of carbonyl groups on the surfaces, while the formation rate and selectivity of $\mathrm{CO}$ and $\mathrm{CO}_{2}$ is proportional to the amount of $\mathrm{CO}_{2}$ desorbed in the TPD-MS experiments.

An induction period is often observed during ODH reactions. In order to further understand the nature of the increased activity of CNFs during the induction period, a method proposed by Boehm [32,117] was adopted to selectively introduce the basic groups. The carbon materials were exposed an oxygen flow containing $2 \% \mathrm{H}_{2} \mathrm{O}$. The induction period almost disappears on the pre-treated sample compared to the as-grown sample. TPD-MS spectra indicate that much more released CO from the CNFs with $\mathrm{H}_{2} \mathrm{O}$ oxidation than from the as-grown CNFs. In contrast, very small but almost equal amounts of released $\mathrm{CO}_{2}$ are observed on the as-grown $\mathrm{CNFs}$ and the pre-treated sample. It confirms that basic groups are selectively introduced to the CNF surfaces by Boehm method and it clearly supports the role of the basic groups as the active sites in the oxidative dehydrogenation of ethylbenzene reaction. The induction period is a result of a gradual development of basic groups on the CNF surface during ODE in the presence of oxygen [46].

It can be argued that the deposited carbon during reaction could be the active sites also on CNFs. However, HRTEM examination did not detect any coke on the surface of the tested CNF sample [46]. In contrast, clear edges of CNF the microstructure are observed, which is in good agreement with literature [108]. Therefore, it can be concluded that the basic oxygen groups on the edges and defects of carbon nanomaterials are the main active sites. The structure of carbon nanomaterials is thus expected to have a remarkable influence on the catalyst activity and the selectivity in oxidative dehydrogenation reactions, which will be discussed later.

There are large efforts devoted to the functionalization of CNTs to increase the amount of oxygen groups on carbon surfaces thus to increase the activity of CNTs in oxidative reactions. Ball milling was employed to produce more sectional defects located on exposed edges or terminals of MWCNTs. These defects can induce the creation of more hydroxyl groups by an alkali-assisted hydroxylation. The as-prepared hydroxylated MWCNTs exhibit twice the catalytic activity of MWCNTs without ball milling [76]. Functionalization of MWCNTs by ozonation was developed to increase BET surface area and modify the surface with respect to increasing the catalytic activity of the samples in oxidative dehydrogenation of ethylben- zene to styrene [74]. Ozonation led to MWCNT-based catalysts revealing conversion and selectivity values of $80 \%$ and $92 \%$, respectively. $\mathrm{NO}_{2}$ as an oxidative agent can efficiently react with MWCNTs and sequentially introduces large quantities of oxygen functional groups on the surface [83]. $\mathrm{UV} / \mathrm{H}_{2} \mathrm{O}_{2}$ oxidative treatment generated hydroxyl radicals can significantly increase the amount of hydroxyl and carbonyl groups onto the surface of carbon nanotubes, leading to an improvement in the catalytic behavior [73].

In conclusion, the results from TPD-MS and XPS are consistent and both points to the importance of the carbonyl, $\mathrm{C}=0$ group in the ODH reaction, which have been identified as the active sites. XPS provides more detailed assessments on the type of the oxygen group. On the other hand, the CO amount in the TPD-MS spectra can be used as a quantitative measurement of the active sites for the oxidative dehydrogenation of ethylbenzene. Selective functionalization such as steam [46], $\mathrm{N}_{2} \mathrm{O}$ [83], and $\mathrm{UV} / \mathrm{H}_{2} \mathrm{O}_{2}$ treatment [73] can selectively introduce the $\mathrm{C}=\mathrm{O}$ into carbon surfaces.

\subsubsection{Reaction mechanism of oxidative dehydrogenation of ethylbenzene}

A reaction mechanism of the ODE over CNFs was proposed as shown in Fig. 5. The reaction might occur via [66,108]: (i) ethylbenzene adsorption at the graphite step edges; (ii) ethylbenzene reaction with the oxygenated species also located at the graphite step edges leading to the dehydrogenation of ethylbenzene to styrene by the scission of $\mathrm{C}-\mathrm{H}$ bond of its ethyl-group; (iii) the simultaneous transformation of the dehydrogenating oxygen species to hydroxyl groups which remains at the graphite edges; (iv) styrene desorption; (v) gas-phase oxygen activation on the basal planes of the graphene layers; (vi) oxygen diffusion to the prismatic planes with the hydroxyl groups; (vii) reformation of the basic chinoidic oxygen functionalities from the activated oxygen and hydroxyl groups; and (viii) water desorption.

Zhang et al. [106] performed kinetic studies of oxidative dehydrogenation of ethylbenzene on carbon nanotubes and

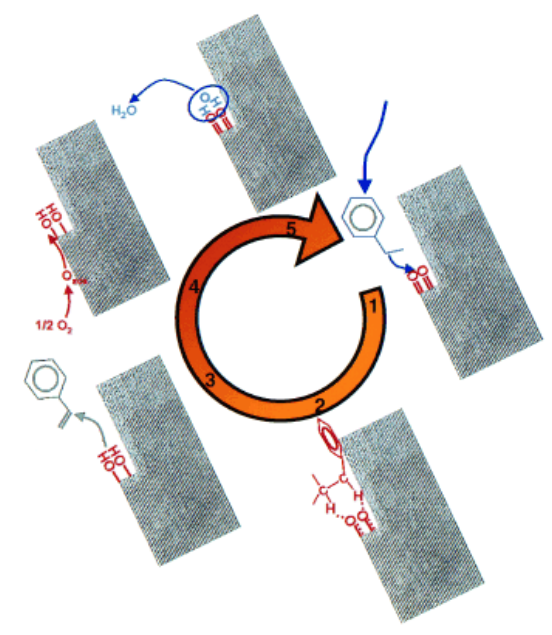

Fig. 5. Mechanism of the catalytic oxidative dehydrogenation over carbon nanofilaments. (1) Adsorption of ethylbenzene; (2) Dehydrogenation at basic centers; (3) Desorption of styrene; (4) Adsorption of oxygen and reaction with OH groups; (5) Desorption of water [108]. 
nanodiamonds. The experimental data were fitted into differently proposed kinetic rate expressions (Langmuir-Hinshelwood, Eley-Rideal, or surface redox reactions). The kinetic data agreed well with the dual-site Langmuir-Hinshelwood model including dissociative adsorption of oxygen molecules and noncompetitive adsorption between ethylbenzene and oxygen molecules. In this mechanism, the overall reaction rate is kinetically limited by the rate of the surface reaction, which mainly involves breaking of two $\mathrm{C}-\mathrm{H}$ bonds in ethylbenzene at the $\alpha$ and $\beta$ positions.

The mechanism was further evidenced by isotopic transient kinetic study, where the reactant mixture from $\mathrm{C}_{6} \mathrm{H}_{5} \mathrm{C}_{2} \mathrm{H}_{5}$ / $\mathrm{O}_{2} / \mathrm{He}$ was switched to $\mathrm{C}_{6} \mathrm{D}_{5} \mathrm{C}_{2} \mathrm{D}_{5} / \mathrm{O}_{2} / \mathrm{He}$. The technique has been widely used to reveal whether or not a particular bond is directly involved in the rate-limiting step [106]. The reaction rate decreased from 16.7 to $11.9 \mathrm{mmol} \mathrm{g}^{-1} \mathrm{~h}^{-1}$ over carbon nanotube after switching the reactant mixture from $\mathrm{C}_{6} \mathrm{H}_{5} \mathrm{C}_{2} \mathrm{H}_{5} / \mathrm{O}_{2} / \mathrm{He}$ to $\mathrm{C}_{6} \mathrm{D}_{5} \mathrm{C}_{2} \mathrm{D}_{5} / \mathrm{O}_{2} / \mathrm{He}$ at $723 \mathrm{~K}$. This result demonstrates a clear kinetic isotopic effect $\left(R_{\mathrm{H}} / R_{\mathrm{D}}=1.4\right)$ and confirmed the relevance of $\mathrm{C}-\mathrm{H}$ bond activation in the reaction mechanism.

\subsubsection{Effects of the structures of carbon nanomaterials}

The reaction mechanism of ODE as discussed in the last section reveals that the surface reaction on carbon surface is a dynamic process. Oxygen groups on the surface, which could be formed before or in-situ during the reaction, are crucial to the activity and selectivity of oxidative dehydrogenation reactions. Carbon is a fascinating material, which have several allotropic forms. As discussed in Section 2, the carbon atoms at defects and edges have different reactivities to oxidation. In addition, the electronic state of surface carbon could influence the surface oxygen properties which will influence the catalyst activity and selectivity as well as the stability in oxidative hydrogenation reactions. On the other hand, it will provide an opportunity to tune the catalytic performance by manipulating the carbon nanostructures.

The catalytic properties of lamp soot, graphite, and CNF were tested in a fixed bed reactor for the ODE to styrene [108]. Figure 6 displays the catalytic properties of the investigated carbon materials with time on stream. The activity of soot was high initially but deactivated very rapidly. The stability of graphite and CNF were much better than soot, mainly due to the better stability towards combustion. The activity increased initially with time on stream possibly due to the build-up of oxygen groups on the carbon surface as active sites. The selectivity to styrene is in the order: CNFs $(85 \%)>$ graphite $(80 \%)>$ soot $(65 \%)$. Therefore, CNF has the best yield of styrene among the three carbon materials. The graphite is the thermodynamically most stable allotropic form of carbon, which has a very good stability in the reaction. Carbon nanofiber or filamentous carbon combined the good stability and high surface area, which seems to be a promising catalyst for the reaction.

Onion like carbons (OLC) [62,66,107], CNTs [66], nanodiamonds [62], graphitic carbon [118], and few layer graphene [119] have been reported to also be very active and stable for the ODE to styrene. At the same conditions, the yield of styrene

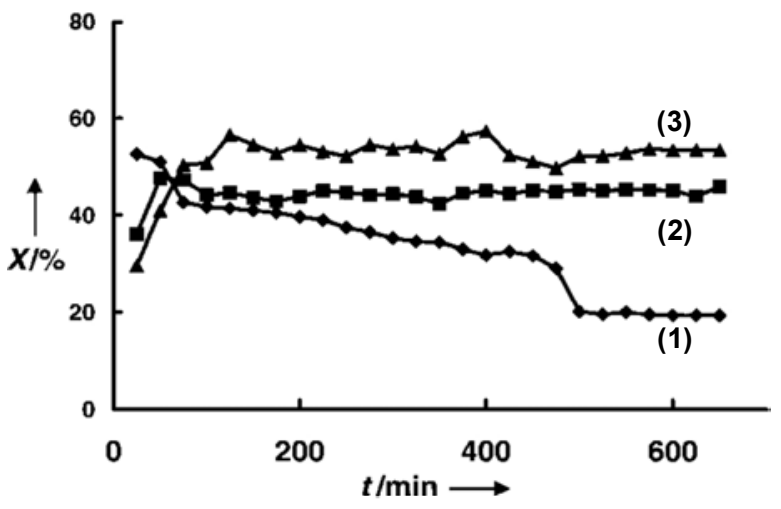

Fig. 6. The styrene yield from soot (1), graphite (2), and nanofilaments (3) with time on stream in the oxidative dehydrogenation of ethylbenzene at $820 \mathrm{~K}$ [108].

on OLC was found to be higher than the yield on CNF, graphite and also higher than one on the commercial K-Fe oxide catalysts. The OLC catalyst exhibited an initial activity developing into conversion levels of $92 \%$ after an activation period of about $2 \mathrm{~h}$ on stream. The stable styrene selectivity of $68 \%$ allowed high styrene yields of $62 \%$, as shown in Fig. 7.

$\mathrm{Su}$ and coworkers [106] made a smart design of the experiment to provide insight to the reaction mechanism of oxidative dehydrogenation of ethylbenzene on both carbon nanotubes and nanodiamonds. It was found that both nanotubes and nanodiamonds were very active towards styrene formation. The detailed kinetic study revealed identical activation energy and an almost identical specific reaction rate for the ODE on both nanomaterials. Electron energy-loss near edge structure (ELNES) spectroscopy was used to study the carbon K-edge of nanotubes and nanodiamonds before and after reaction to provide a quantitative measurement of the $\mathrm{sp}^{2} / \mathrm{sp}^{3}$ ratio, where the ELNES of highly orientated pyrolitic graphite (HOPG) samples were used as reference. Two spectral features centered at approximately 292 and $285 \mathrm{eV}$ approximately indicate $\sigma^{*}$ and $\pi^{*}$ transitions, the latter is typical for graphite or $\mathrm{sp}^{2}$-bond carbon [106]. After $1800 \mathrm{~min}$ on stream, the specific fine structure for

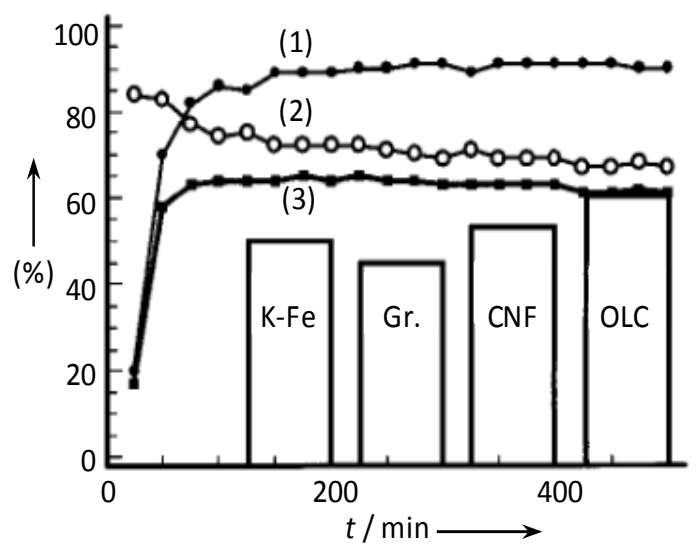

Fig. 7. Performance of onion like carbons (OLC) in the $\mathrm{ODH}$ of ethylbenzene at $790 \mathrm{~K}$ with time on stream. (1) Ethylbenzene conversion; (2) Selectivity to styrene; (3) Styrene yield. Steady-state styrene yields for graphite (Gr.), carbon nanofilaments (CNF), and the industrial $\mathrm{K} \pm \mathrm{Fe}$ catalyst are also given. Data are given relative to the catalyst mass [62]. 
the nanotube and the nanodiamond remained, indicating a high stability of the carbon nanomaterials against oxidation at the reaction conditions. However, the fraction of $\mathrm{sp}^{2}$-carbon in the nanotube decreased from $80 \pm 3 \%$ to $75 \pm 5 \%$ and that of $\mathrm{sp}^{3}$-carbon in nanodiamond decreased from $93 \pm 1 \%$ to $87 \pm 3 \%$. It indicates that both $\mathrm{sp}^{2}$-nanotube and $\mathrm{sp}^{3}$-nanodiamond have similar active sites comprising both $\mathrm{sp}^{2}$ - and $\mathrm{sp}^{3}$-hybridized carbon atoms. It explains also well why similar selectivity to styrene was obtained on both carbon structures. A very high selectivity of about $95 \%$ to styrene was reported at $723 \mathrm{~K}$ on both carbon nanotubes and nanodiamonds in a differential reactor, at relatively low conversions [106]. However, a much lower selectivity to styrene was observed at $790 \mathrm{~K}$ but high conversions ( $>80 \%$ ). It should be noticed that the selectivity to styrene decreased with increasing conversion [107].

For conventional carbon such as activated carbons, the activity and selectivity have long been correlated to the surface area and porosity of the carbon. However, the porosity has only small effects on the activity and selectivity for the ODE on carbon nanomaterials, due to the mesoporous structure. The activity is in general proportional to the surface area since the specific reaction rate is normally constant on different structured carbon nanomaterials.

The graphitic sheet orientation can be used to adjust the ratio between the prismatic and basal plane on the edges of CNFs, which can control the amount of surface oxygen groups and their properties. For instance, the outer surface of tubular CNF (CNT) is mostly composed of the basal planes whereas platelet CNF has the edge sites only. As we reviewed previously, electronic density sate of carbon atoms at edges of CNFs could be influenced by the ratio between the prismatic and basal plane. Edge structures may also control the kinetics of prismatic surface oxidation and decarboxylation, and thus the red-ox catalytic cycle. As a consequence, it is expected that the ratio between the prismatic and the basal plane of the carbon nanofibers will be an important parameter for the rational catalyst design of catalytic reactions involving red-ox processes, such as oxidative dehydrogenation.

$\mathrm{CNF}$ is a promising catalyst candidate for oxidative dehydrogenation reactions to match the above requirements, due to a large fraction of edge areas, and a tunable ratio between the prismatic and the basal plane of the carbon nanofibers. Zhao et al. [46] systematically studied the influences of the graphene sheet orientation of CNFs in terms to the CNF axis on both activity and selectivity for the oxidative dehydrogenation of ethylbenzene. CNFs have been tested for the oxidative dehydrogenation reaction in a fixed bed reactor at $673 \mathrm{~K}$ and a partial pressure of ethylbenzene of $2.4 \mathrm{kPa}$ [46]. Three typical carbon nanofibers such as tubular, fishbone and platelet were selected to tune the ratio of the prismatic and basal surfaces, where the average angels of the graphite sheet in terms of the axis of the nanofiber are 0,45 , and 90, respectively. Another fishbone nanofiber with an angle of $20^{\circ}$ was also tested. The average angle was used as the sample code.

The textural properties, the amount of desorbed CO in TPD and the estimated oxygen density are summarized in Table 3. The results in Table 4 illustrated the significant effect of the surface structure of CNFs on the catalyst activity and selectivity. Table 4 shows that the activity follows the order: CNF20 > CNF45 > CNF90 > CNF00, while the selectivity to styrene follows the order: CNF20 > CNF45 > CNF00 > CNF90. CNF20 is clearly the best catalyst, especially in terms of selectivity. All the CNF catalysts were found to be stable during the reaction due to high degree of graphitization, in contrast to a fast deactivation of activated carbon.

The density of oxygen groups (Table 3 ) is similar for all CNFs (CNF20 to CNF90), except for CNF45 which has a slightly higher density. The high activity of CNF20 is contributed by both the high surface area and high reactivity of the active site [46].

As far as the fishbone CNF (CNF20, CNF45) structures are concerned, both the edge sites and the basal plane of the graphitic sheets are exposed to the reactants. Thus, active sites of oxygen-containing species can be formed on the edge sites at the tip of the graphitic sheets, and the adsorption of ethylben-

Table 4

Conversions, selectivities, and yields of styrene during ODE over CNF catalysts [46].

\begin{tabular}{lccccc}
\hline CNF code & $X_{\mathrm{EB}} / \%$ & $S_{\mathrm{ST}} / \%$ & $Y_{\mathrm{ST}} / \%$ & $S_{\mathrm{To}} / \%$ & $S_{\mathrm{CO} 2} / \%$ \\
\hline CNF00 & $26.45 \pm 2.38$ & $77.23 \pm 2.18$ & $20.42 \pm 1.34$ & 1.21 & 19.76 \\
CNF20 & $58.12 \pm 1.14$ & $84.96 \pm 1.28$ & $49.38 \pm 0.75$ & 1.24 & 12.90 \\
CNF45 & $48.47 \pm 3.51$ & $80.12 \pm 2.12$ & $38.83 \pm 1.36$ & 1.17 & 18.41 \\
CNF90 & $42.25 \pm 2.79$ & $70.56 \pm 1.28$ & $30.98 \pm 1.16$ & 1.29 & 26.95 \\
CNF20-HT & $40.23 \pm 1.32$ & $86.67 \pm 1.05$ & $34.84 \pm 1.41$ & 1.20 & 12.35 \\
CNF45-HT & $35.12 \pm 1.14$ & $80.86 \pm 1.69$ & $28.38 \pm 1.75$ & 1.32 & 17.90 \\
\hline
\end{tabular}

$X$, Conversion of EB, $X=\left(N_{\mathrm{EB}, \text { in }}-N_{\mathrm{EB}, \text { out }}\right) / N_{\mathrm{Ebin}} \times 100 \%$.

$S$, Selectivity to product, $S_{\mathrm{P}}=N_{\mathrm{P}} /\left(N_{\mathrm{EB}, \mathrm{in}}-N_{\mathrm{EB}, \text { out }}\right) \times 100 \%$.

$Y$, Yield of ST, $R=N_{\mathrm{ST}} / N_{\text {Ebin }} \times 100 \%$.

$N$, mol/h.

EB: ethylbenzene; ST: styrene; To: Toluene.

Table 3

Textural properties including surface area $\left(S_{\mathrm{CNF}}\right)$, total pore volume $\left(V_{\mathrm{p}}\right)$, and micropore volume $\left(V_{\mathrm{mp}}\right)$ and oxygen-containing groups of used CNFs with different microstructures [46].

\begin{tabular}{|c|c|c|c|c|c|c|}
\hline \multirow{2}{*}{ Code } & \multirow{2}{*}{$\begin{array}{c}S_{\mathrm{CNF}} \\
\left(\mathrm{m}^{2} / \mathrm{g}\right)\end{array}$} & \multirow{2}{*}{$\begin{array}{c}V_{\mathrm{P}} \\
\left(\mathrm{cm}^{3} / \mathrm{g}\right)\end{array}$} & \multirow{2}{*}{$\begin{array}{c}V_{\mathrm{mp}} \\
\left(\mathrm{cm}^{3} / \mathrm{g}\right)\end{array}$} & \multirow{2}{*}{$\begin{array}{c}\mathrm{CO}_{\text {desorbed }}{ }^{\mathrm{a}} \\
\left(\mu \mathrm{mol} / \mathrm{g}_{\mathrm{CNF}}\right)\end{array}$} & \multicolumn{2}{|c|}{$\mathrm{CO}_{\text {density }}$} \\
\hline & & & & & $\mu \mathrm{mol} / \mathrm{m}^{2}$ & 0 atom $/ \mathrm{nm}^{2}$ \\
\hline CNF00 & 93.4 & 0.332 & 0.000 & 176.4 & 1.88 & 1.13 \\
\hline CNF20 & 132.3 & 0.449 & 0.001 & 554.8 & 4.19 & 2.52 \\
\hline CNF45 & 52.1 & 0.219 & 0.000 & 262.1 & 5.03 & 3.02 \\
\hline CNF90 & 88.5 & 0.224 & 0.000 & 391.2 & 4.41 & 2.65 \\
\hline CNF20-HCl b & 136.3 & 0.452 & 0.000 & 582.3 & 4.27 & 2.56 \\
\hline CNF45-HCl & 53.9 & 0.223 & 0.001 & 283.7 & 5.26 & 3.16 \\
\hline
\end{tabular}

aThe desorbed amount of CO is measured by TPD-MS.

${ }^{\mathrm{b}} \mathrm{HCl}$ : pretreated in $\mathrm{HCl}(3 \mathrm{~mol} / \mathrm{L})$ for three days at room temperature for removal of metals. 
zene can take place on the basal planes. The adsorption of aromatic molecules is favored by the delocalization and the hybridization of $\pi$ electrons between the nanotubes and the adsorbed molecules. In addition, a proper $\pi$-stacking interaction between the aromatic carbon ring in the CNF and the phenyl group in EB can possibly activate the $\mathrm{C}-\mathrm{H}$ bond in the ethyl group. The dual site adsorption of ethylbenzene with the edge site and basal plane on the $\mathrm{CNF}$, might result in an optimized transition state for the reaction, and thus the high activity. Interaction between ethylbenzene and CNFs depends also on the oxygen density. In addition, the electron density of carbon near and at the edge of the graphene sheets depends on the ratio of carbon atoms at the basal planes and at the edges on the CNF surfaces. As a consequence, it makes the oxygen groups more nucleophilic, and thus increases the selectivity to styrene.

The most exciting finding of the above cited works is that it is possible to manipulate the selectivity of oxidative dehydrogenation by tuning the graphene sheet orientation or more precisely the ratio of carbon atoms at the edges of the CNF surfaces and the basal planes. The fishbone CNFs have much higher selectivity to styrene than platelet and tubular CNFs. Among the fishbone CNFs, CNF20 has the highest selectivity. It corresponds well to the observation that a very small amount of $\mathrm{CO}_{2}$ releases in TPD on CNF20, suggesting a low amount of carboxyl, carboxylic anhydride, peroxide and lactones groups. These groups could catalyze the deep oxidation leading to formation of $\mathrm{CO}$ and $\mathrm{CO}_{2}$. As we summarized in Section 2, the formation of such oxygen group could involve carbon fragments on the edge or adjunct carbon atoms with relatively large space such as armchair sites [39]. The termination of the graphene edge could influence the formation as well as the reactivity of the oxygen groups. It can be speculated that the structure of fishbone might suppress the formation of carbon fragments. Therefore, it is worth to study experimentally the more detailed structure of graphene termination, in order to gain a better understanding of the formation mechanism of oxygen groups at the edge of graphene.

It can be summarized that both the edge sites and the basal plane on graphene sheet contribute to higher conversion of ethylbenzene on fishbone. Therefore, it is crucial to use a material with an optimum ratio between the edge and basal sites. Based on the reaction mechanism, the following factors should be matched by the oxidative dehydrogenation of ethylbenzene catalyst, as a result of the rational design for the oxidative dehydrogenation of ethylbenzene reaction [46]: (1) A high density of the surface basic groups per gram of the catalyst, to achieve a better activity; (2) Higher crystallinity of the carbon materials, to achieve a better stability; (3) Control of the ratio between the two kinds of active sites, basic quinone groups on the edges and aromatic rings of the graphite sheets on CNFs, or (4) control $\mathrm{sp}^{2} / \mathrm{sp}^{3}$ ratio of hybrid nanodiamond carbon, to achieve a better selectivity to styrene.

\subsection{Carbon-mediated oxidative dehydrogenation of propane} (ODP)

The global demand for light alkenes has increased due to the increasing demand of the corresponding polymers. Their shortage in the market is the main driving force for the renewed interest in producing them from alkanes, which are generally easily available and used as low-cost feedstock for chemical production.

Dehydrogenation has been used by industry for the production of light alkenes like ethene, propene, and butene, and so on. However, all these reactions are reversible and suffer from several limitations [60]: (1) Thermodynamic restriction on conversion and selectivity; (2) Strong endothermic main reaction and necessity to supply heat at high temperature; (3) Coke formation and resulting catalyst deactivation. ODH of alkanes has been considered as an alternative for production alkenes to overcome these limitations. Selective oxidation of hydrogen during oxidative dehydrogenation can supply the heat in-situ and shift the thermodynamic limitation. It makes it possible to operate at much lower temperatures. This in turn will reduce the side reactions, such as cracking of alkanes and coke formation and thus increases the selectivity.

ODH has its own drawbacks, such as the difficulty of controlling the consecutive oxidation of alkanes/alkenes to carbon oxides due to much higher reactivity of products than the reactants. The key issue in catalysts development is therefore to activate only the $\mathrm{C}-\mathrm{H}$ bonds of an alkane molecule [60].

Reducible transition metal oxides and alkali and alkaline earth ions and oxides have widely been used as catalysts for oxidative dehydrogenation of light alkanes such as ethane, propane, $n$-butane, etc. Vanadium and molybdenum oxides usually are the main elements present in catalysts used for oxidative dehydrogenation of propane (ODP) [60,120]. B/P oxides, Ga/zeolite, and Sn/P oxides are also used as the catalysts [60]. The catalysts and their catalytic performance for oxidative dehydrogenation of propane were summaries by Cavani and Trifiro [120], as shown in Fig. 8.

A general feature of most catalytic systems is that the selectivity to propylene decreases with increasing the propane conversion (Fig. 8). This is likely due to the presence of labile allylic hydrogen atoms in the formed propylene which act as centers for consecutive oxidative attacks [120], making it very difficult to develop catalysts with a high yield of propene.

Sui et al. [100,101,121] explored CNF into oxidative dehydrogenation of propane. The effects of carbon structures, surface chemistry and surface modification with phosphoric oxides on oxidative dehydrogenation of propane were intensively studied. Recently the oxidative dehydrogenation of propane reaction has been intensively studied addressing effects of surface functionalization and different structures of carbon nanomaterials [83,109,110,122-125] and ordered mesoporous carbon $[109,122-124]$.

\subsubsection{Reaction mechanism}

Tang et al. [110] have studied the chemical structures of the active sites and catalytic mechanisms for oxidative dehydrogenation of propane on the basal plane of graphene oxide (GO) by DFT calculations. The epoxy groups on the graphene oxide were identified as active sites for the $\mathrm{C}-\mathrm{H}$ bond activation. It was found that the first $\mathrm{C}-\mathrm{H}$ bond breaking of propane through 


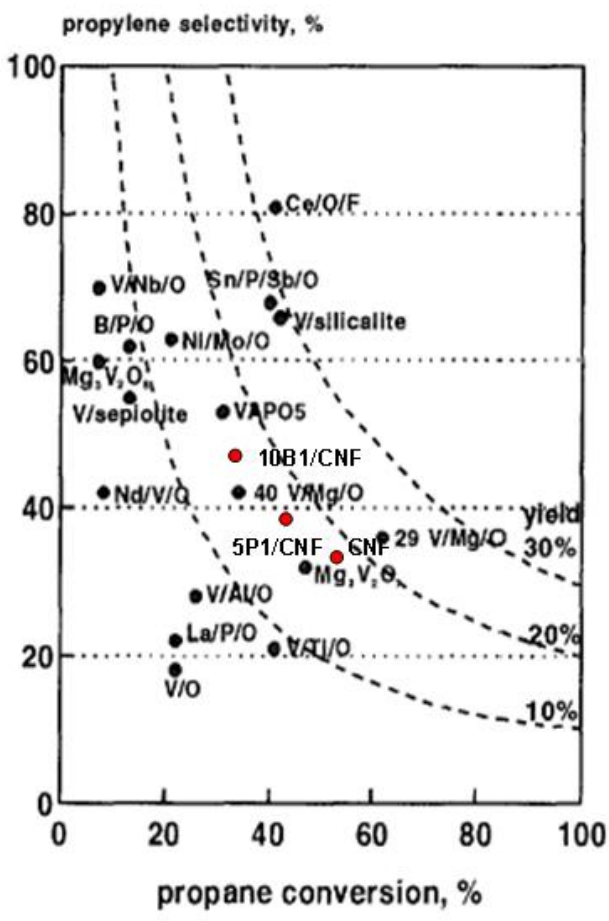

Fig. 8. Best yields of propylene reported in the literature for the various catalysts [120], where the data on CNFs was from Ref. [121].

$\mathrm{H}$ abstraction by epoxide leading to the formation of a propyl radical was the rate-determining step. More importantly, the activation energy of the first $\mathrm{H}$ abstraction $(94-100 \mathrm{~kJ} / \mathrm{mol}$ ) depends significantly on the number of $\mathrm{OH}$ groups around the active site. $\mathrm{OH}$ groups around the active sites significantly reduce the activation energy (about $75 \mathrm{~kJ} / \mathrm{mol}$ ). However, the reoxidation or regeneration of the active sites was not investigated. Schlögl and coworkers [43] performed a systematic DFT analysis of the interaction of hydrocarbon molecules with quinone groups in all stable multiplicity states of the carbon clusters. The importance of quinone groups on the ODP has been also demonstrated experimentally by selectively introducing quinone groups by $\mathrm{NO}_{2}$ activation of CNT [83]. On the graphene-like carbon clusters with oxygen saturated zigzag and armchair edges, the product of the first elementary step of the reaction, either hydrocarbon radical or surface ether, is found to be strictly dependent on the spin multiplicity. The activation energy of the first $\mathrm{H}$ abstraction in oxidative dehydrogenation of propane is about $45 \mathrm{~kJ} / \mathrm{mol}$, while the activation energy of the second $\mathrm{H}$ abstraction is higher $(75-97 \mathrm{~kJ} / \mathrm{mol})$ which is the rate-limiting step on the oxygen saturated zigzag sites. The armchair edge is passive towards reaction with hydrocarbons, but it reacts almost without a barrier with hydrocarbon radicals. It suggests an importance of the transport and readsorption of intermediates within the overall process. The barrier of reoxidation of zigzag sites by $\mathrm{O}_{2}$ was found to decrease from 161 to $69 \mathrm{~kJ} / \mathrm{mol}$ with increasing level of saturation with $\mathrm{H}$ atoms, while the barrier of reoxidation of armchair sites by $\mathrm{O}_{2}$ is much lower (about $75 \mathrm{~kJ} / \mathrm{mol}$ ).

In summary, the oxidative dehydrogenation reaction depends significantly on the structure of carbon materials. The activation energy and rate determining step could also depend on the active sites and structure of the carbon nanomaterial. The edge sites are more active for the oxidative dehydrogenation of propane reaction, but the reaction is fully site termination dependent. Both zigzag and armchair sites are active sites responsible for the first and second $\mathrm{H}$ abstraction steps, respectively. DFT investigations of side reactions such as deep oxidation of propane and propene need to be investigated in future.

\subsubsection{Effects of the structure of CNFs}

Similar to oxidative dehydrogenation of ethylbenzene, different carbon materials such as graphite, CNF and active carbon were compared as the catalysts for oxidative dehydrogenation of propane. The results are summarized in Fig. 9 [121]. It reveals that the reaction rates follow an order: activated carbon $>\mathrm{CNFs}>$ graphitic carbon. The yield of propene is higher crystallinity of the carbon materials has a significant effect on activity and selectivity. Moreover, CNF and graphite catalysts have a much better stability than activated carbon. The graphite carbon has a relatively high stability but a low activity to propene due to low surface area, while the active carbon has a relatively high conversion due to the high surface area but low selectivity and stability. CNF combines the advantages of graphite carbon such as high crystallinity of graphite as well as the advantage of active carbon such as high surface area. As a result, high activity and high selectivity and thus high yield of propene, as well as a high stability can be obtained on CNFs.

The effect of the nanostructure of the CNFs on oxidative dehydrogenation of propane were also investigated by Sui et al. in terms of activity, selectivity and stability $[100,121]$. Two types
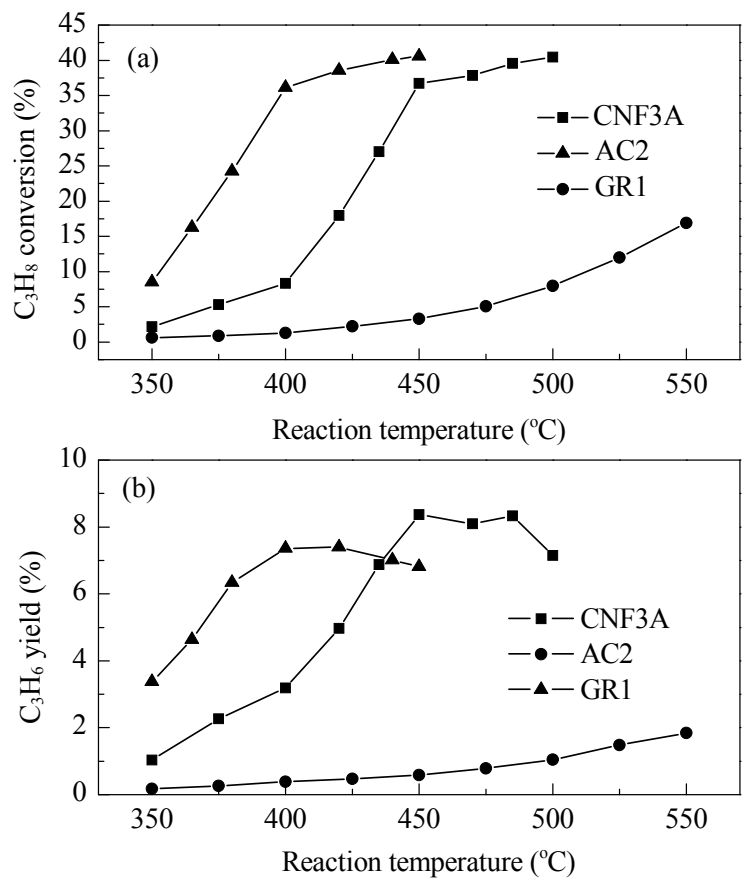

Fig. 9. Propane conversion (a) and propene yield (b) as a function of reaction temperature over carbon catalysts. CNF: carbon nanofiber; AC: activated carbon; GR: graphitic carbon [121]. 
of carbon nanofibers with different graphene sheet orientations, namely fishbone and tubular CNFs, were used in the investigation. The texture properties are summarized in the Table 5 . The surface area and pore volume are very similar for the two CNFs. The catalytic tests were performed in a fixed-bed reactor, and the results are listed in Table 6, indicating that graphene sheet orientation of CNFs has a significant influence on both activity and selectivity in oxidative dehydrogenation of propane. The fishbone CNF has higher activity and selectivity to propene than the tubular CNF or CNT. Boehm titration was used to investigate the surface oxygen amount and distribution on the surface of the CNFs. The amount of total oxygen and basic oxygen groups of CNFs after used in oxidative dehydrogenation of propane reaction are listed in Table 6 . The larger amount of oxygen groups, especially the larger amount of $\mathrm{C}=\mathrm{O}$ groups on the F-CNF than on the T-CNF result in a higher activity on the F-CNF (Table 6).

It is still a great challenge to gain the propene selectivity in the oxidative dehydrogenation of propane due to high reactivity of propene. The typical yield of propene is less that $20 \%$ on the different CNFs, which is the new type of the carbon catalysts. The catalytic behavior is not superior to the metal catalysts, as shown in Fig. 8. However, CNF catalysts show a clear advantage, namely good stability. Similar to oxidative dehydrogenation of ethylbenzene, the conversion of propane increased little with time on stream. The induction period is corresponding to the generation of necessary active sites by the surface oxidation of CNF. In the induction period, the selectivity to $\mathrm{CO}_{2}$ and $\mathrm{CO}$ is relatively high. The selectivity to $\mathrm{CO}_{2}$ and $\mathrm{CO}$ decreased while the selectivity to propene increased gradually with time on stream.

Sui et al. [101] designed experiments combining TPD and temperature-programmed surface reaction (TPSR) of propane to assess the role of the basic oxygen groups. TPD spectra were used to determine categories and amounts of surface oxygen complexes on CNF. In the sequential TPD in a temperature range of $423 \mathrm{~K}$ and $1273 \mathrm{~K}$ after a TPD up to $923 \mathrm{~K}, 0.90$

Table 5

Properties of CNFs and amount of oxygen groups obtained by Boehm titration [100].

\begin{tabular}{lccccc}
\hline \multirow{2}{*}{ Sample } & $\begin{array}{c}A \\
\left(\mathrm{~m}^{2} / \mathrm{g}\right)\end{array}$ & $\begin{array}{c}V \\
\left(\mathrm{~cm}^{3} / \mathrm{g}\right)\end{array}$ & $\begin{array}{c}V_{\mathrm{M}} \\
\left(\mathrm{cm}^{3} / \mathrm{g}\right)\end{array}$ & \multicolumn{2}{c}{$A_{\mathrm{o}} /(\mathrm{mmol} / \mathrm{g})$} \\
\hline F-CNF & 141.6 & 0.589 & 0.008 & 1.01 & 0.91 \\
T-CNF & 139.4 & 0.278 & 0.003 & 0.60 & 0.53 \\
\hline
\end{tabular}

$A$-Surface area, $V$-Pore volume, $V_{\mathrm{m}}$-Micropore volume, $A_{\mathrm{o}}$-Amount of surface oxygen complexes obtained after reaction at $823 \mathrm{~K}$ for $5 \mathrm{~h}$.

Table 6

Catalytic performance of different CNFs in oxidative dehydrogenation of propane [100].

\begin{tabular}{lcccccc}
\hline \multirow{2}{*}{ Sample } & $X\left(\mathrm{C}_{3} \mathrm{H}_{8}\right)$ & \multicolumn{4}{c}{ Selectivity $(\omega / \%)$} & $Y\left(\mathrm{C}_{3} \mathrm{H}_{6}\right)$ \\
\cline { 3 - 6 } & $(\%)$ & $\mathrm{C}_{3} \mathrm{H}_{6}$ & $\mathrm{CO}_{2}$ & $\mathrm{CO}$ & $\mathrm{C}_{2}$ & $(\%)$ \\
\hline F-CNF & 44.9 & 33.0 & 41.7 & 24.3 & 1.0 & 14.8 \\
T-CNF & 20.2 & 29.8 & 55.5 & 14.2 & 0.6 & 6.0 \\
T-CNF-OX & 25.8 & 41.6 & 44.3 & 13.2 & 1.0 & 10.7 \\
\hline
\end{tabular}

Reaction conditions: $q v(\mathrm{Ar})=88 \mathrm{ml} / \mathrm{min}, q v\left(\mathrm{O}_{2}\right)=8 \mathrm{ml} / \mathrm{min}, q v\left(\mathrm{C}_{3} \mathrm{H}_{8}\right)=$ $4 \mathrm{ml} / \mathrm{min}, m(\mathrm{CNF})=0.4 \mathrm{~g}, T=823 \mathrm{~K}$. T-CNF-OX-T-CNF treated in $\mathrm{H}_{2} \mathrm{SO}_{4}-\mathrm{NHO}_{3}$. $\mathrm{mmol} / \mathrm{g} \mathrm{CO}$ but no $\mathrm{CO}_{2}$ is desorbed from the F-CNF surfaces [100]. It indicates that almost all the acidic groups on the surfaces were removed in the first TPD up to $923 \mathrm{~K}$. Two CO desorption peaks could be found centered at 1073 and $1223 \mathrm{~K}$, which can be assigned to carbonyl-like groups and basic oxides according to references $[126,127]$. The structure of basic oxides on carbonaceous materials is not unambiguous, but it always contains $\mathrm{C}=\mathrm{O}$ bonds [100].

The assessment of $\mathrm{C}=0$ groups in oxidative dehydrogenation were performed by TPSR in the mixture of propane and $\mathrm{Ar}$ (8 vol\%) in the absence of gas phase oxygen on CNFs (Fig. 10) where all the acidic groups are removed by TPD experiments up to $923 \mathrm{~K}$. Propene is selectively produced above $623 \mathrm{~K}$. When the temperature was further increased, $\mathrm{CO}$ and $\mathrm{CO}_{2}$ were formed. The results point out that selectively oxidative dehydrogenation can be obtained in the anaerobic condition at relatively low temperatures (less than $698 \mathrm{~K}$ ). When all the surface oxygen removed in Ar up to $1273 \mathrm{~K}$, no propene can be detected in the TPRS experiments. The reaction mechanism of ODP seems to be similar to ODE. The adsorbed propane reacts with the oxygenated species on the graphite step edges leading to the dehydrogenation of propane by scission of $\mathrm{C}-\mathrm{H}$ bonds, while the oxygen species are transformed to hydroxyl groups which remains at the graphite edges. In addition, oxidation of propene occurs at a lower temperature in the TPRS reaction of propene, as shown in Fig. $10(\mathrm{~b})$, indicating that propene is more active than propane (Fig. 10(a)). It explains well the challenge to obtain high selectivities to propene in the ODP reac-
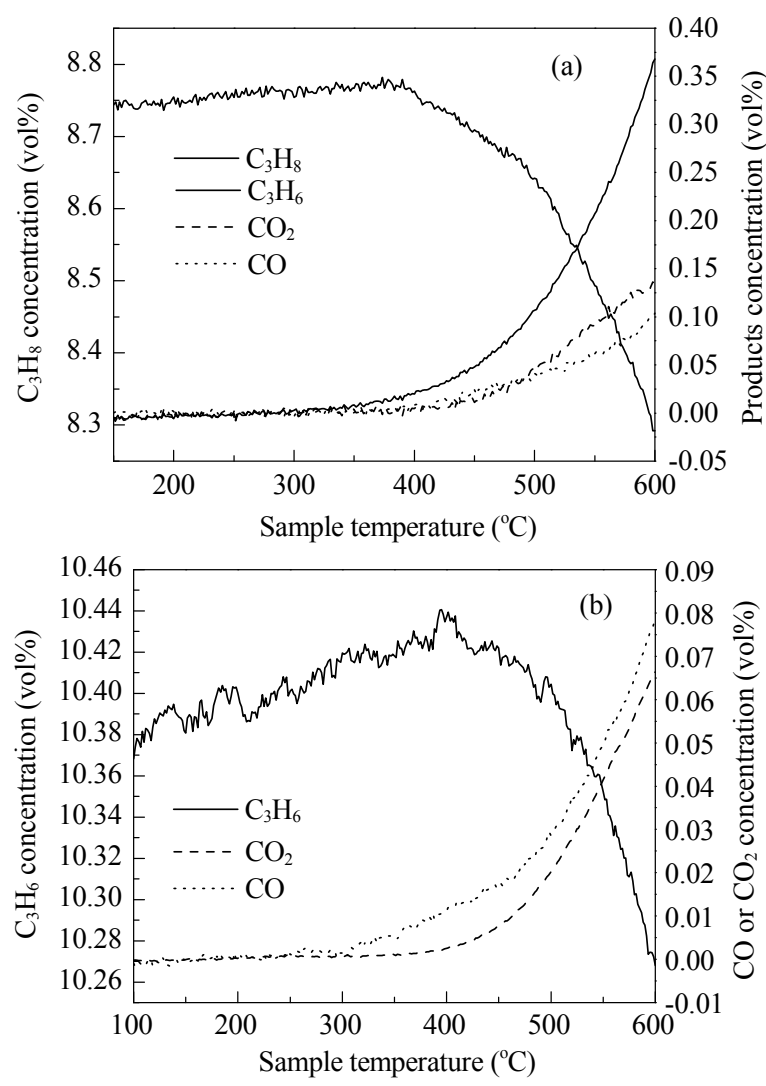

Fig. 10. TPSR of $\mathrm{C}_{3} \mathrm{H}_{8}$ (a) and $\mathrm{C}_{3} \mathrm{H}_{6}$ (b) on F-CNF1, 0.186 g catalysts [121]. 
tion.

Similar to ODE, the ratio of basal to edge atoms of CNFs has significant effects on not only activity but also selectivity. The density of edge sites on CNFs determines the density of oxygen sites, leading to differences of catalytic performances. The fishbone CNF has a much larger number of edge sites compared to carbon nanotubes, thus higher activity. Most interesting observation is that selectivity to propene is generally lower on CNT than that on fishbone CNFs as shown in Table 6 as well as in Fig. 11.

The results reveal that the well-structured carbon nanomaterials are superior catalysts for ODP. It has been shown that the presence of disordered carbon on CNTs is detrimental to the catalytic performance as it allows for unwanted functional groups occurring in parallel with the formation of the selective ketonic active sites [72]. From the point of providing basal to edge atom ratio, fish-bone CNF is the most promising candidate as catalyst for oxidative dehydrogenation of propane. Fishbone CNF with a graphite sheet angel of 15-25 in terms of fiber axis, with liquid $\mathrm{HNO}_{3}$ oxidation was testified to be the most effective catalyst for oxidative dehydrogenation of propane [100] Over this catalyst, a 35\% propene selectivity was achieved at propane conversion of $54 \%$ under $823 \mathrm{~K}$, which is comparable to the best metal oxide catalyst.

\subsubsection{Oxidative dehydrogenation of propane on $P-, B-$, and $\mathrm{N}$-doped CNFS}

Previous studies have revealed that $\pi$ electron interaction between alkens and graphite plays an important role for alkene chemisorption [55], resulting in preferred chemisorption of propene than propane. It leads to a formidable challenge in improving the selectivity to propene in the ODH. Analysis of the reaction mechanism pointed out that both the reactivity of absorbed propane/propene and oxygen were key factor for controlling activity and selectivity. Too high reactivity of adsorbed oxygen will result in a high selectivity to $\mathrm{CO}$ and $\mathrm{CO}_{2}$ instead of propene. As discussed above, adsorbed oxygen has different reactivity at different edge sites [39], indicating that the activity

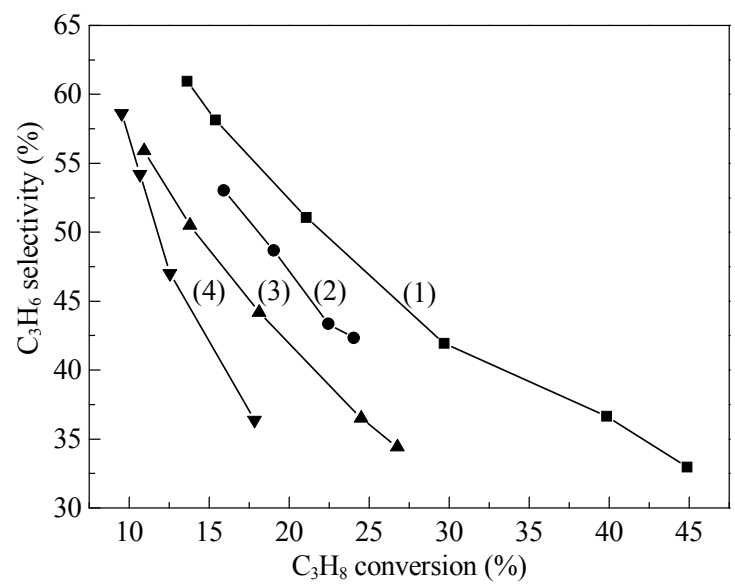

Fig. 11. Relationship between propane conversion and propene selectivity on different CNFs at different reaction conditions. (1) F-CNF, 773 $\mathrm{K}, \mathrm{O}_{2} / \mathrm{C}_{3} \mathrm{H}_{8}=2$; (2) F-CNF, $773 \mathrm{~K}, \mathrm{O}_{2} / \mathrm{C}_{3} \mathrm{H}_{8}=0.5$; (3) F-CNF, $773 \mathrm{~K}$ $\mathrm{O}_{2} / \mathrm{C}_{3} \mathrm{H}_{8}=2$; (4) T-CNF, $773 \mathrm{~K}, \mathrm{O}_{2} / \mathrm{C}_{3} \mathrm{H}_{8}=2$ [121]. and selectivity of ODH might depend on the termination of edges of the graphite sheets in the CNFs, or more precisely on the ratio of armchair and zigzag sites. It has been long recognized that B- and P-doped graphite or carbon materials have a high resistance. More interestingly it seems that phosphorus and boron have preferred blocking sites such as armchair and zigzag sites, respectively [128]. It can therefore provide new opportunities for improving the selectivity to propene during the reaction.

Sui et al. [101,121] tested B and P doping to improve the selectivity in oxidative propane dehydrogenation on CNFs. The CNF samples were pretreated in concentrated $\mathrm{HNO}_{3}$ for $7 \mathrm{~d}$. The supported catalysts were prepared by wet impregnation of $\mathrm{H}_{3} \mathrm{BO}_{3}$ and $\mathrm{H}_{3} \mathrm{PO}_{4}$ in the solution of ethanol. After impregnation and drying, the samples were calcined in Ar at $1073 \mathrm{~K}$ for $2 \mathrm{~h}$ and in air at $873 \mathrm{~K}$ for $2 \mathrm{~h}$. Different loading of $\mathrm{B}$ and $\mathrm{P}$ oxides and different resources of $\mathrm{B}$ and $\mathrm{P}$ have been also studied. The protection of oxidation of CNFs by means of B and P doping has been clearly evidenced by temperature programmed oxidation (TPO) where the temperature at the maximum oxidation rate followed in an order of P-CNF > B-CNF - CNF [101]. The results revealed that the resistance of oxidation of $\mathrm{P}$ - and $\mathrm{B}$-doped $\mathrm{CNF}$ is higher than pristine CNFs.

TPSR was also performed to identify the effects of $B$ and $P$ doping on oxidative dehydrogenation of propane over CNFs. By comparing Fig. 12 with Fig. 10, it can clearly be noticed that a slightly lower propane conversion but much lower selectivity to $\mathrm{CO}$ and $\mathrm{CO}_{2}$ are obtained on both B- and P-doped CNFs (Fig. 12(a) and (b)). The oxidation of propene is more significantly suppressed. The starting temperature of the oxidation of propene to $\mathrm{CO}$ and $\mathrm{CO}_{2}$ is much higher on the doped samples (Fig. 12(c) and (d)). But it increased rather rapidly with increasing temperature, meaning high activation energy for oxidation of propene to $\mathrm{CO}$ and $\mathrm{CO}_{2}$ on doped samples. More interestingly, the staring oxidation temperature of oxidation is higher and reaction rate of propene oxidation is lower on $\mathrm{P}$ doped CNFs (Fig. 12(d)) than B doped CNFs (Fig. 12(c)).

The fact that the selective blockage of the surface armchair sites by $\mathrm{P}$ groups resulted in suppressing of the $\mathrm{CO}_{2}$ formation might indicate that the adjunct oxygen on the front of armchair sites or oxygen between the armchair sites are preferred sites for $\mathrm{CO}_{2}$ formation from propene. It is in good agreement with the observation that the stability and reactivity of oxygen depends on the carbon-carbon spacing [41]. Direct formation of $\mathrm{CO}_{2}$ from propane seems to be not selective, and the ratio of $\mathrm{CO}_{2}$ and $\mathrm{CO}$ is almost one. The difference between the oxidation of propane and propene can possibly be related to different active sites for propane and propene reactions.

The effect of B and P doping of CNFs on propane oxidative dehydrogenation is more clearly demonstrated in Fig. 13, where the selectivity at an identical conversion follows the order of $\mathrm{P}-\mathrm{CNF}>\mathrm{B}-\mathrm{CNF}>\mathrm{CNF}[101,121]$. The selectivity to $\mathrm{CO}_{2}$ is the lowest and selectivity to propene is highest on the P-CNFs which are in good agreement with TPRS data, indicating that secondary reaction of propene to $\mathrm{CO}_{2}$ is suppressed. In addition, it has been reported that the oxidative dehydrogenation of propane reaction are very stable at $798 \mathrm{~K}$ [101]. 

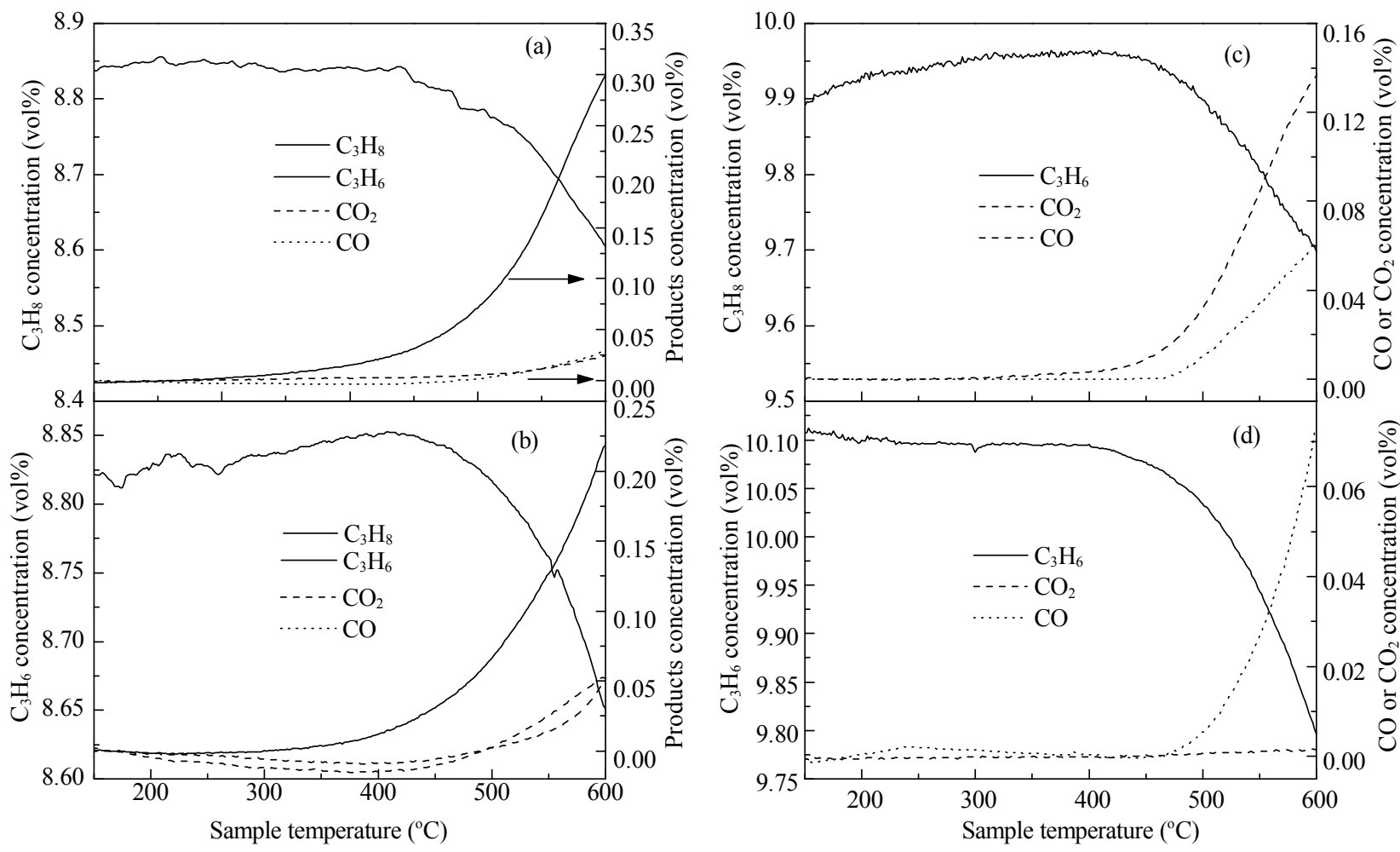

Fig. 12. TPSR of propane on $10 \mathrm{wt} \% \mathrm{~B} / \mathrm{CNF}$ (a) and $5 \mathrm{wt} \% \mathrm{P} / \mathrm{CNF}$ (b) and TPSR of propene on $10 \mathrm{wt} \% \mathrm{~B} / \mathrm{CNF}$ (c) and $5 \mathrm{wt} \% \mathrm{P} / \mathrm{CNF}$ (d) [121].

Recently Su and coworkers [129] reported the doping of CNTs with nitrogen, can efficiently enhance the catalytic performance of the ODP. The graphitic nitrogen was suggested to play a determining role in enhancing the catalytic activity by decreasing the overall activation energy and speeding up the activation of oxygen. More interestingly, N-doped CNTs increases propene selectivity at the same conversion level compared to CNTs. DFT investigation revealed that the incorporated $\mathrm{N}$ atoms in CNTs can reduce the gap between the highest-occupied molecular orbitals and the lowest-unoccupied molecular orbitals, which would make the electron transfer from the CNT to the adsorbed oxygen species easy [130]. The three-coordinated substitutional $\mathrm{N}$ atoms induce sharp localized states above the Fermi level due to the presence of addi-

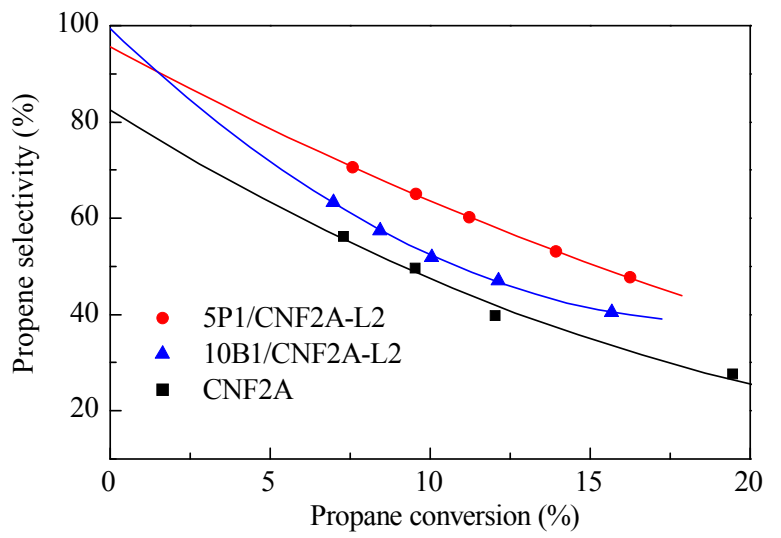

Fig. 13. Changes in propene selectivity with propane conversion at 723 K [101]. tional electrons, since that nitrogen has one electron more than C [131]. Therefore, substitutional N doping in CNTs should result in n-type conducting behavior, and make adsorbed surface oxygen species more nucleophilic. As a result, it enhanced selective $\mathrm{C}-\mathrm{H}$ bond activation leading to propene production.

The results clearly illustrate that selective blockage of armchair by $\mathrm{P}$ doping of CNFs and electron rich $\mathrm{N}$ doping CNT or $\mathrm{CNF}$ are powerful methods to improve the selectivity to propene and improve the catalyst stability by means of suppressing the gasification of CNFs even at temperatures as high as 823 K.

\subsection{Carbon-mediated oxidative dehydrogenation of i-butane (ODB)}

Similar to oxidative dehydrogenation of propane, transition metals have been widely used in oxidative dehydrogenation of $i$-butane which is an important industrial precursors for producing synthetic rubbers, plastics and chemicals $[44,60,132]$. Despite an intensive research due to the importance of the industrial application, the reaction is still limited by the selectivity, as the common challenge in oxidative dehydrogenation. In the line of oxidative dehydrogenation of ethylbenzene and propane using CNT, Su and coworkers have reported oxidative dehydrogenation of $i$-butane on carbon nanotubes $[45,78]$. The oxidative dehydrogenation of butane reaction was also reported on graphene [119] and graphitic carbons [133-135]. It was found that the commercial CNT is more stable than iron and activated carbon as catalysts [78], and also as shown in Fig. 14 [45]. Oxidation of CNFs in liquid $\mathrm{HNO}_{3}$ increased the yield of 


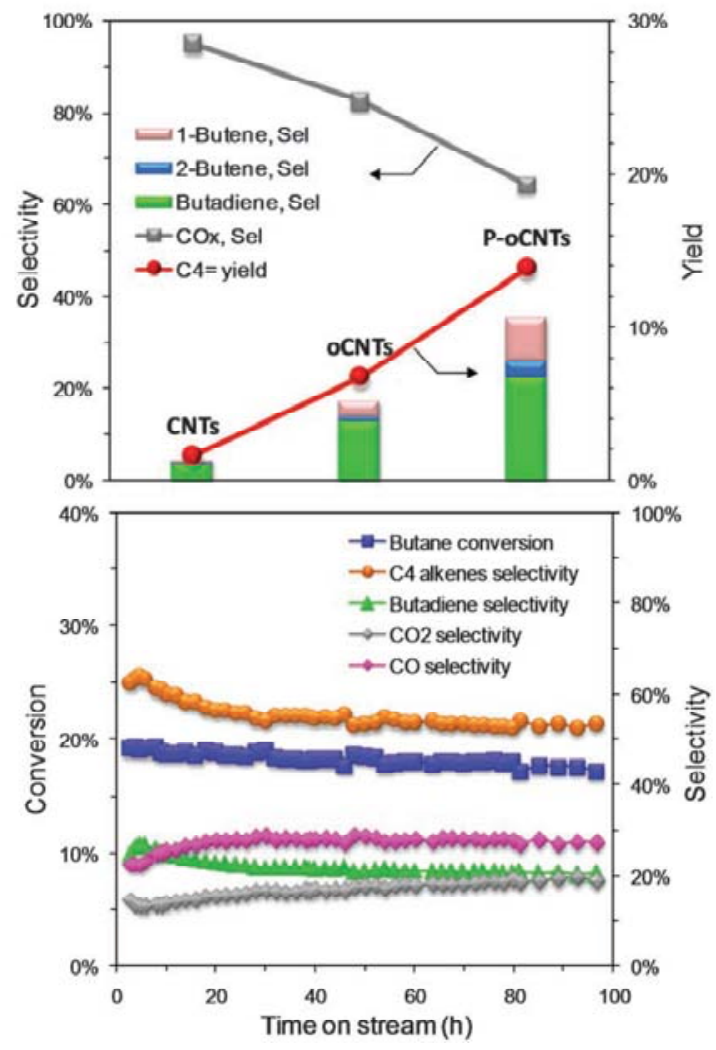

Fig. 14. Performance of various CNTs for oxidative dehdyrogenation of butane under oxygen-rich conditions. Catalyst $0.18 \mathrm{~g}, 0.67 \%$ butane, $\mathrm{O}_{2} /$ butane $=2,15 \mathrm{ml} / \mathrm{min}, 673 \mathrm{~K}[45]$.

butadiene, and doping CNT with P further increased the selectivity. A survey of recent literature showed that the P-oCNTs catalyst is as selective as the best $\mathrm{V} / \mathrm{MgO}$ catalyst [78] developed during the past 20 years (Fig. 15) [45].

Two peaks of oxygen groups [45], namely ketonic $\mathrm{C}=0$ groups $(531.2 \pm 0.2 \mathrm{eV})$ and C- 0 groups $(533.1 \pm 0.2 \mathrm{eV})$ (i.e., ether and hydroxyl) were identified by XPS study. Using in-situ $\mathrm{XPS}$, ketonic $\mathrm{C}=\mathrm{O}$ groups were identified as the main active sites responsible for oxidative dehydrogenation.

DFT calculations were performed to obtain a better under-

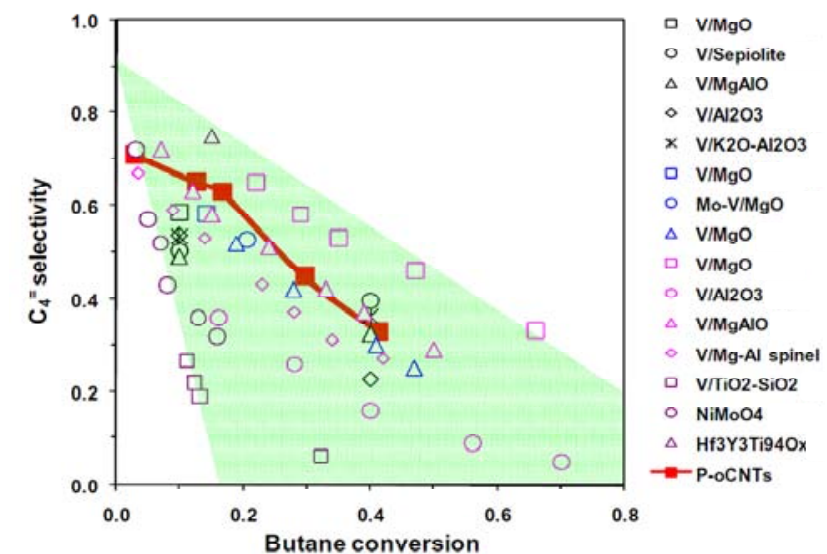

Fig. 15. Comparison of selectivities to $C_{4}$ alkenes over various catalysts in the literature [45]. standing of the reaction mechanism of oxidative dehydrogenation of $i$-butane on CNTs. The results are summarized in Fig. 14(b), where all the adsorption heat of the intermediates were presented but the activation energy was not estimated. The adsorption heat follows the order of butadiene $>2$-butene $>$ 1-butene > butane, which confirm the general trends measured experimentally [55]. The strong adsorption of butadiene on CNT represented a challenge for the selectivity, since it can be further oxidized to $\mathrm{CO}$ and $\mathrm{CO}_{2}$.

Well-nanostructured carbon, such as glassy carbon spheres, SWCNT, graphene, and graphite, have been demonstrated to give high activities in ODB to obtain olefins [134]. However, Pd-containing CNF had superior selectivity for butadiene formation compared to Pd free CNF catalysts. Carbon with graphitic structures was highly selective for propylene and butenes without severe combustion in oxidative dehydrogenation of butane. It has also been shown that the commercial CNTs display a good stability and a promising catalytic activity for the oxidative dehydrogenation reaction of 1-butene to butadiene. Much higher yields of butadiene were obtained on CNT compared to $\alpha-\mathrm{Fe}_{2} \mathrm{O}_{3}$ [78].

Kinetic study pointed out that $\mathrm{CO}_{2}$ is formed both as the primary and the secondary product. Two different active sites appear to be responsible for the oxidative dehydrogenation and the deep oxidation processes separately. However, no clear correlation was observed between the quinone-type functional sites and the selective oxidation product [133].

As discussed in Section 2, the surface oxygen species are classified as electrophilic $\mathrm{O}^{-}$(oxide), $\mathrm{O}_{2}{ }^{-}$(superoxide), and $\mathrm{O}_{2}{ }^{2-}$ (peroxide) and nucleophilic $\left(\mathrm{O}^{2-}\right)$ types. Figure 16 summarizes the proposed mechanism in the CNTs-catalyzed butane oxidation. There are a number of structural defects and terminal carbon fragments in CNTs. Below $873 \mathrm{~K}$, these defect sites or edges of graphene can convert $\mathrm{O}_{2}$ molecules to electrophilic oxygen species [42] and thus cause low selectivity to alkenes.

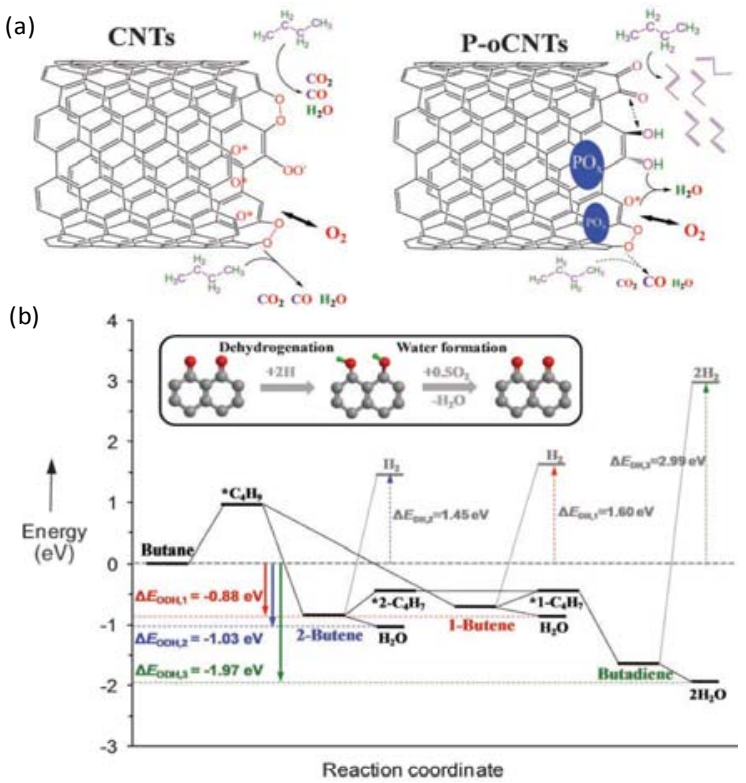

Fig. 16. Schematic reaction (a) and energy steps (b) of butane oxidation on pristine and P-modified CNTs [45]. 
Oxidation in liquid $\mathrm{HNO}_{3}$ of CNTs results in functionalization by $\mathrm{O}^{2-}$ anions into various functional groups. Nucleophilic groups such as $\mathrm{C}-\mathrm{OH}$ and $\mathrm{C}=\mathrm{O}$ are shown in Fig. 16(a) right side. These could be type II sites classified by TPD experiments as discussed in Section 2 [39]. Ketonic C=0 is a typical nucleophilic species with high electron density, that preferentially reacts with electron-poor saturated bonds leading to selective dehydrogenation. As discussed in section 2, oxygen activity depends on the space between carbon atoms. Similar to the image at the left side in Fig. 16(a), it can be speculated that the electrophilic oxygen such as $\mathrm{O}_{2}{ }^{-}$(superoxide), and $\mathrm{O}_{2}{ }^{2-}$ (peroxide) are stabilized preferably on armchair sites due to steric reason. These groups could belong to type I groups classified experimentally [39]. It has also been discussed above that P groups can selectively block the armchair sites [51]. Reaction of P groups with such sites of CNT can reduce the electrophilic oxygen formation [45]. So far we are not able to control precisely the terminal configurations of the graphene during growth of CNFs. There typically is a mixture of armchair and zigzag termination on the edge of CNFs. On zigzag sites, nucleophilic oxygen $\left(\mathrm{O}^{2-}\right)$ like ketonic $\mathrm{C}=\mathrm{O}$ is possibly dominating. This might also explain why $\mathrm{P}$ doping is more effective than $\mathrm{B}$ doping in oxidative dehydrogenation of propane in terms of improving propene selectivity. Therefore, it might provide a new direction in future to improve the selectivity by means of controlled synthesis of CNT/CNF with controlled termination or by means of precisely controlled blockage of armchair sites.

\section{Summary and perspectives}

Over the past few years, significant efforts have been devoted to the study of new carbon mediated catalysis, more precisely carbon mediated oxidative dehydrogenation reactions of ethylbenzene, ethane, propane and butane. The works have been focused on reaction mechanism, catalytic performance of different carbon nanomaterials such as graphite, diamond, onion-like carbon, CNF, CNT, graphene as well as B and P doped carbon nanomaterials. The carbon nanomaterials with high graphitic degree have obviously superior stability compared to activated carbon. Thanks to the intensive study of carbon mediated oxidative dehydrogenation reactions, carbon nanomaterials have achieved similar activity as metal oxide cata- lysts. However, like most of metal oxide catalyzed oxidative dehydrogenation reactions, low selectivity at high conversion levels still limits the commercialization of the metal-free catalyzed oxidative dehydrogenation reactions. The oxidative dehydrogenation of ethylbenzene is a prospectively alternative to the direct catalytic dehydrogenation, which is the core process step in the highly efficient and technically mature production of styrene. High conversion and high selectivity of styrene (close to $90 \%$ ) have been obtained on the carbon nanomaterials. Carbon mediated oxidative dehydrogenation of ethylbenzene has also a high potential for industrial application. For the oxidative dehydrogenation of propane and butane, the yields obtained are still far from being interesting for industrial implementation.

There has been a large progress on DFT investigation of oxidative dehydrogenation on carbon surfaces. It provides a better understanding of the interaction between oxygen and carbon surfaces and edge sites and reaction mechanism of oxidative dehydrogenation. However, a better understanding of the most important mechanistic aspect of deep oxidation leading to $\mathrm{CO}$ and $\mathrm{CO}_{2}$ formation is still missing. More DFT studies in future are highly encouraged, which could make better rational design of the catalysts to achieve better selectivity.

\section{Acknowledgements}

The financial supports from the Norwegian Research Council, the 111299 Project of Ministry of Education of China (B08021), and the European Commission FP-7 Project FREECATS (Grant agreement no.: 280658) are gratefully acknowledged.

\section{References}

[1] Coughlin R W. Ind Eng Chem Prod Res Dev, 1969, 8: 12

[2] Stueber F, Font J, Fortuny A, Bengoa C, Eftaxias A, Fabregat A. Top Catal, 2005, 33: 3

[3] Radovic L R, Rodriguez-Reinoso F. Chem Phys Carbon, 1997, 25: 243

[4] Rodriguez-Reinoso F. In: Patrick J W Ed. Porosity in Carbons. UK: Wiley, 1995. 253

[5] Ros T G, Van Dillen A J, Geus J W, Koningsberger D C. Chem Eur J, 2002, 8: 1151

\section{Graphical Abstract}

Chin. J. Catal., 2014, 35: 824-841 doi: 10.1016/S1872-2067(14)60120-0

\section{Carbon mediated catalysis: A review on oxidative dehydrogenation}

De Chen*, Anders Holmen, Zhijun Sui, Xinggui Zhou Norwegian University of Science and Technology, Norway; East China University of Science and Technology, China

Developments of carbon mediated oxidative dehydrogenation are reviewed in terms of fundamental studies on adsorption, reaction mechanism as well as effects of carbon nanomaterial structures and surface functional groups on the catalytic performance.

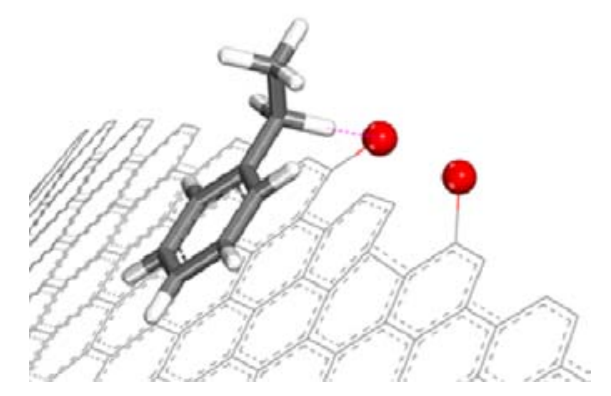


[6] Serp P, Figueiredo J L. Carbon Materials for Catalysis. Hoboken: John Wiley \& Sons, Inc., 2008

[7] Serp P, Corrias M, Kalck P. Appl Catal A, 2003, 253: 337

[8] Dai H J. Surf Sci, 2002, 500: 218

[9] Terrones M. Int Mater Rev, 2004, 49: 325

[10] Mostofizadeh A, Li Y W, Song B, Huang Y D. J Nanomater, 2011: 685081

[11] Terrones M, SouzaF, Antonio G, Rao A M. Top Appl Phys, 2008, 111: 531

[12] Tessonnier J-P, Su D S. ChemSusChem, 2011, 4: 824

[13] De Jong K P, Geus J W. Catal Rev-Sci Eng, 2000, 42: 481

[14] Zhao M Q, Zhang Q, Huang J Q Wei F. Adv Funct Mater, 2012, 22: 675

[15] Vilatela J J, Eder D. ChemSusChem, 2012, 5: 456

[16] Serp P, Castillejos E. ChemCatChem, 2010, 2: 41

[17] Zhu J, Holmen A, Chen D. ChemCatChem, 2013, 5: 378

[18] Guldi D M, Martín N. Carbon Nanotubes and Related Structures: Synthesis, Characterization, Functionalization, and Applications. Weinheim: Wiley-VCH, 2010

[19] Su D S, Zhang J, Frank B, Thomas A, Wang X C, Paraknowitsch J, Schlögl R. ChemSusChem, 2010, 3: 169

[20] Su D S, Perathoner S, Centi G. Chem Rev, 2013, 113: 5782

[21] Sun X Y, Wang R, Su D S. Chin J Catal (孙晓岩, 王锐, 苏党生. 催化 学报), 2013, 34: 508

[22] Yu D S, Nageli E, Du F, Dai L M. J Phy Chem Lett, 2010, 1: 2165

[23] Zhou K, Li B, Zhang Q, Huang J Q, Tian G L, Jia J C, Zhao M Q, Luo G H, Su D S, Wei F. ChemSusChem, 2014, 7: 723

[24] Zhou J H, Sui Z J, Li P, Chen D, Dai Y C, Yuan W K. Carbon, 2006, 44: 3255

[25] Kvande I, Zhu J, Zhao T J, Hammer N, Rønning M, Raaen S, Walmsley J C, Chen D. J Phys Chem C, 2010, 114: 1752

[26] Kvande I, Øye G, Hammer N, Rønning M, Raaen S, Holmen A, Sjöblom J, Chen D. Carbon, 2008, 46: 759

[27] Zhu J, Zhao T J, Kvande I, Chen D, Zhou X G, Yuan W K. Chin J Catal (朱俊, 赵铁均, KVANDE I, 陈德, 周兴贵, 袁渭康. 催化学报), 2008, 29: 1145

[28] Kvande, I, Chen D, Zhao T J, Skoe I M, Walmsley J C, Ronning M. Top Catal, 2009, 52: 664

[29] Duan X Z, Zhou J H, Qian G, Li P, Zhou X G, Chen D. Chin J Catal (段 学志, 周静红, 钱刚, 李平, 周兴贵, 陈德. 催化学报), 2010, 26: 979

[30] Schlögl R. In: Ertl G, Knoezinger H, Weitkamp J eds. Preparation of Solid Catalysts. Weinheim: Wiley-VCH, 1999.138

[31] Maciá-Agullój A, Cazorla-Amorós D, Linares-Solano A, Wild U, Su D S, Schlögl R. Catal Today, 2005, 102-103: 248

[32] Boehm H P. Carbon, 1994, 32: 759

[33] Klein K L, Melechko A V, McKnight T E, Retterer S T, Rack P D, Fowlkes J D, Joy D C, Simpson M L. J Appl Phys, 2008, 103: 061301/1

[34] Efremenko I, Sheintuch M. J Catal, 2003, 214: 53

[35] Ulbricht H, Moos G, Hertel T. Surf Sci, 2003, 532-535: 852

[36] Radovic L, Rodriguez-Teinoso F. In: Thrower P A Ed. Chemistry, Physics of Carbon. New York: Marcel Dekker, 1997

[37] Sorescu D C, Jordan K D, Avouris P. J Phys Chem B, 2001, 105: 11227

[38] Du Y Y, Li Z H, Fan K N. Chin J Catal (杜钰珏, 李振华, 范康年. 催 化学报), 2013, 34: 1291

[39] Hart P J, Vastola F J, Walker P L Jr. Carbon, 1967, 5: 363

[40] Suenaga K, Koshino M. Nature, 2010, 468: 1088

[41] Sherman A, Eyring H.J Am Chem Soc, 1932, 54: 2661

[42] Atamny F, Bloecker J, Duebotzky A, Kurt H, Timpe O, Loose G, Mahdi W, Schlögl R. Mol Phys, 1992, 76: 851
[43] Khavryuchenko O V, Frank B, Trunschke A, Hermann K, Schlögl R. J Phys Chem C, 2013, 117: 6225

[44] Madeira L M, Portela M F. Catal Rev-Sci Eng, 2002, 44: 247

[45] Zhang J, Liu X, Blume R, Zhang A H, Schlögl R, Su D S. Science, 2008, 322: 73

[46] Zhao T J, Sun W Z, Gu X Y, Rønning M, Chen D, Dai Y C, Yuan W K, Holmen A. Appl Catal A, 2007, 323: 135

[47] Mckee D W. Chem Phys Carbon, 1981, 16: 1

[48] Wu XX, Radovic L R. Carbon, 2006, 44: 141

[49] Chen D, Moljord K, Holmen A. Microporous Mesoporous Mater, 2012, 164: 239

[50] Wang X, Xie Y C. Reac Kinet Catal Lett, 2000, 70: 43

[51] Oh S G, Rodriguez N M. J Mater Res, 1993, 8: 2879

[52] McKee D W, Spiro C L, Lamby E J. Carbon, 1984, 22: 285

[53] Rodriguez N M, BAKER R T K. J Mater Res, 1993, 8: 1886

[54] Garcia-Bordeje E, Pereira M F R, Ronning M, Chen D. Catalysis, 2014, 26: 72

[55] Hoffman W P, Vastola F J, Walker P L Jr. Carbon, 1984, 22: 585

[56] Frank B, Wrabetz S, Khavryuchenko O V, Blume R, Trunschke A, Schlögl R. ChemPhysChem, 2011, 12: 2709

[57] Castillejos E, Bachiller-Baeza B, Rodríguez-Ramos I, Guerrero-Ruiz A. Carbon, 2012, 50: 2731

[58] Cavani F, Trifirò F. Appl Catal A, 1995, 133: 219

[59] Cavani F, Ballarini N, Cericola A. Catal Today, 2007, 127: 113

[60] Grabowski R. Catal Rev-Sci Eng, 2006, 48: 199

[61] Håkonsen S F, Holmen A. In: Ertl G, Knözinger H, Schüth F, Weitkamp J eds. Handbook of Heterogeneous Catalysis. Weinheim: Wiley-VCH, 2008. 3384

[62] Su D S, Maksimova N I, Mestl G, Kuznetsov V L, Keller V, Schlögl R, Keller N. Carbon, 2007, 45: 2145

[63] Suzuki T, Nakagawa K. JJpn Petrol Inst, 2011, 54(2): 66

[64] Cao Y H, Luo X Y, Yu H, Peng F, Wang H J, Ning G Q. Catal Sci Technol, 2013, 3: 2654

[65] Pereira M F R, Figueiredo J L, Órfão J J M, Serp P, Kalck P, Kihn Y. Carbon, 2004, 42: 2807

[66] Su D S, Maksimova N, Delgado J J, Keller N, Mestl G, Ledoux M J, Schlögl R. Catal Today, 2005, 102-103: 110

[67] Resasco D E. Nat Nanotechnol, 2008, 3: 708

[68] Su D S, Chen X W, Liu X, Delgado J J, Schlögl R, Gajovic A. Adv Mater, 2008, 20: 3597

[69] Nigrovski B, Scholz P, Krech T, Qui N V, Pollok K, Keller T, Ondruschka B. Catal Commun, 2009, 10: 1473

[70] Delgado J J, Chen X, Tessonnier J P, Schuster M E, Del Rio E, Schlögl R, Su D S. Catal Today, 2010, 150: 49

[71] Frank B, Rinaldi A, Blume R, Schlögl R, Su D S. Chem Mater, 2010, 22: 4462

[72] Rinaldi A, Zhang J, Frank B, Su D S, Abd Hamid S B, Schlögl R. ChemSusChem, 2010, 3: 254

[73] Qui N V, Scholz P, Krech T, Keller T F, Pollok K, Ondruschka B. Catal Commun, 2011, 12: 464

[74] Qui N V, Scholz P, Keller T F, Pollok K, Ondruschka B. Chem Eng Technol, 2013, 36: 300

[75] Yuan H, Liu H Y, Diao J Y, Gu X M, Su D S. New Carbon Mater, 2013, 28: 336

[76] Rao R C, Yang M, Ling Q, Li C S, Zhang Q Y, Yang H X, Zhang A M. Catal Sci Technol, 2014, 4: 665

[77] Xia W, Hagen V, Kundu S, Wang Y M, Somsen C, Eggeler G, Sun G G, Grundmeier G, Stratmann M, Muhler M. Adv Mater, 2007, 19: 3648

[78] Liu X, Su D S, Schlögl R. Carbon, 2008, 46: 547

[79] Zhang J, Comotti M, Schüth F, Schlögl R, Su D S. Chem Commun, 2007: 1916

[80] Arrigo R, Hävecker M, Schlögl R, Su D S. Chem Commun, 2008: 
4891

[81] Zhang J, Müller J O, Zheng W Q, Wang D, Su D S, Schlögl R. Nano Lett, 2008, 8: 2738

[82] Zhang J, Hu, Y S, Tessonnier J P, Weinberg G, Maier J, Schlögl R, Su D S. Adv Mater, 2008, 20: 1450

[83] Chen C L, Zhang J, Peng F, Su D S. Mater Res Bull, 2013, 48: 3218

[84] Frank B, Morassutto M, Schomaecker R, Schlögl R, Su D S. ChemCatChem, 2010, 2: 644

[85] Ewels C P, Glerup M. J Nanosci Nanotechnol, 2005, 5: 1345

[86] Herrero M A, Prato M. Mol Cryst Liq Cryst, 2008, 483: 21

[87] Lan Y C, Wang Y, Ren Z F. Adv Phys, 2011, 60: 553

[88] Rummeli M H, Bachmatiuk A, Borrnert F, Schaffel F, Ibrahim I, Cendrowski K, Simha-Martynkova G, Placha D, Borowiak-Palen E, Cuniberti G, Buchner B. Nanoscale Res Lett, 2011, 6: 303

[89] Tarasov B P, Muradyan V E, Volodin A A. Russ Chem Bull, 2011, 60: 1261

[90] Li B, Su D S.J Phys Chem C, 2013, 117: 17485

[91] Rao R C, Zhang Q Y, Liu H D, Yang H X, Ling Q, Yang M, Zhang A M, Chen W. J Mol Catal A, 2012, 363-364: 283

[92] Guo X F, Kim J H, Kim G J. Catal Today, 2011, 164: 336

[93] Xia W, Yin X L, Kundu S, Sánchez M, Birkner A, Wöll C, Muhler M. Carbon, 2011, 49: 299

[94] Zhang J, Su D S, Schlögl R. Phys Status Solid B, 2009, 246: 2502

[95] Nigrovski B, Zavyalova U, Scholz P, Pollok K, Müller M, Ondruschka B. Carbon, 2008, 46: 1678

[96] Xia W, Hagen V, Kundu S, Wang Y M, Somsen C, Eggeler G, Sun G G, Grundmeier G, Stratmann M, Muhler M. Adv Mater, 2007, 19: 3648

[97] Zhang Z Y, Cho K. Phys Rev B, 2007, 75: 075420

[98] Li P, Zhao T J, Zhou J H, Sui Z J, Dai Y C, Yuan W K. Carbon, 2005, 43: 2701

[99] Su D S, Chen X W, Weinberg G, Klein-Hofmann A, Timpe O, Abd Hamid S B, Schlögl R. Angew Chem Int Ed, 2005, 44: 5488

[100] Sui Z J, Zhao T J, Zhou J H, Li P, Dai Y C. Chin J Catal (隋志军, 赵铁 均, 周静红, 李平, 戴迎春. 催化学报), 2005, 26: 521

[101] Sui Z J, Zhou J H, Dai Y C, Yuan W K. Catal Today, 2005, 106: 90

[102] Delgado J J, Su D S, Rebmann G, Keller N, Gajovic A, Schlögl R. J Catal, 2006, 244: 126

[103] Delgado J J, Vieira R, Rebmann G, Su D S, Keller N, Ledoux M J, Schlögl R. Carbon, 2006, 44: 809

[104] Li P, Li T, Zhou J H, Sui Z J, Dai Y C, Yuan W K, Chen D. Microporous Mesoporous Mater, 2006, 95: 1

[105] Delgado J J, Chen X. W, Su D S, Hamid S B A, Schlögl R. J Nanosci Nanotechnol, 2007, 7: 3495

[106] Zhang J, Su D S, Zhang A H, Wang D, Schlögl R, Hebert C. Angew Chem Int Ed, 2007, 46: 7319

[107] Keller N, Maksimova N I, Roddatis V V, Schur M, Mestl G, Butenko Y V, Kuznetsov V L, Schlögl R. Angew Chem Int Ed, 2002, 41: 1885
[108] Mestl G, Maksimova N I, Keller N, Roddatis V V, Schlögl R. Angew Chem Int Ed, 2001, 40: 2066

[109] Michorczyk P, Kuśtrowski P, Niebrzydowska P, Wach A. Appl Catal A, 2012, 445-446: 321

[110] Tang S B, Cao Z X. Phys Chem Chem Phys, 2012, 14: 16558

[111] James D H, Castor W M. Ullmanns Encyclopedia of Industrial Chemistry, 5 ed., VCH, Weinheim, 1994

[112] Lisovskii A E, Aharoni C. Catal Rev-Sci Eng, 1994, 36: 25

[113] Oganowski W, Hanuza J, Kepiński L. Appl Catal A, 1998, 171: 145

[114] Emig G, Hofmann H.J Catal, 1983, 84: 15

[115] Zhou J H, Sui Z J, Zhu J, Li P, Chen D, Dai Y C, Yuan W K. Carbon, 2007, 45: 785

[116] Rodríguez-reinoso F. Carbon, 1998, 36: 159

[117] Boehm H P, Diehl E. Zeitschrift Elektrochem, 1962, 66: 642

[118] Schwartz V, Overbury S H, Liang C D. ACS Symposium Series, 2013, 1132: 247

[119] Schwartz V, Fu W J, Tsai Y T, Meyer H M III, Rondinone A J, Chen J H, Wu Z L, Overbury S H, Liang C D. ChemSusChem, 2013, 6: 840

[120] Cavani F, Trifirò F. Catal Today, 1995, 24: 307

[121] Sui Z J. [PhD dissertation]. Shanghai: East China University of Science and Technology, 2005

[122] Liu L, Deng Q F, Agula B, Zhao X, Ren T Z, Yuan Z Y. Chem Commun, 2011, 47: 8334

[123] Liu L, Deng Q F, Liu Y P, Ren T Z, Yuan Z Y. Catal Commun, 2011, 16: 81

[124] Wang Y, Xia W S, Weng W Z. J Xiamen Univ (Nat Sci) (王野, 夏文 生, 翁维正. 厦门大学学报(自然科学版)), 2011, 50: 341

[125] Liu L, Deng Q F, Agula B, Ren T Z, Liu Y P, Zhaorigetu B, Yuan Z Y. Catal Today, 2012, 186: 35

[126] Boehm H P. Carbon, 2002, 40: 145

[127] Figueiredo J L, Pereira M F R, Freitas M M A, Órfão J J M. Carbon, 1999, 37: 1379

[128] Park C, Baker R T K. J Phys Chem B, 1999, 103: 2453

[129] Chen C L, Zhang J, Zhang B S, Yu C L, Peng F, Su D S. Chem Commun, 2013, 49: 8151

[130] Hu X B, Wu Y T, Li H R, Zhang Z B. J Phys Chem C, 2010, 114: 9603

[131] van Dommele S, de Jong K P, Bitter J H. Chem Commun, 2006: 4859

[132] Li L, Yan Z F. Prog Chem (李丽, 阎子峰. 化学进展), 2005, 17: 651

[133] Xie H, Wu Z L, Overbury S H, Liang C D, Schwartz V. J Catal, 2009, 267: 158

[134] Jang D Y, Jang H G, Kim G R, Kim G-J. Res Chem Intermediates, 2011, 37: 1145

[135] Schwartz V, Xie H, Meyer H M III, Overbury S H, Liang C D. Carbon, 2011, 49: 659 